\title{
EFEITOS DO SILICATO DE CÁLCIO E SUA INTERAÇÃO COM O FÓSFORO NO ESTADO NUTRICIONAL, PRODUTIVIDADE E QUALIDADE TECNOLOGICA DA CANA-DE-AÇÚCAR \\ (Caccharum sp.)
}

MARCílIO NOGUEIRA DO AMARAL GURGEL.

Engenheiro-Agrónomo

Orientador: André M. L. Neptune

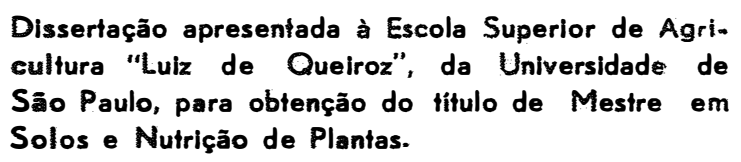

PIRACICABA

Estado de São Paulo - Brasil

Novembro, 1979 
Dedico este trabalho aos meus pais e em especial à minha esposa e filhos. 


\section{$\begin{array}{lllllllllllllll}\text { A } & G & R & A & D & E & C & \text { I } & M & E & N & T & O & S\end{array}$}

Agradeço às seguintes pessoas e instituições:

Professor Dr. André Martin Louis Neptune, pela orientação;

Engo-Agro Geraldo Majela de Andrade Silva. pelo estímulo e apoio;

Professores Doutores Roberto Simionato Moraes, José Paulo Stupie11o e Valdomiro C. Bittencourt;

Engọ-Agrọ Eduardo Guimarães;

Cooperativa Central dos Produtores de Açūcar e Ālcool do Estạ do de São Paulo - Estação Experimental de Cana de Piracicaba, que possibilitou a realização deste trabalho;

Aos funcionários Maurício de Oliveira, José Boldrin, Maria Aparecida J. Banhos e João Novello. 


\section{T $N$ N D I. C E}

Página

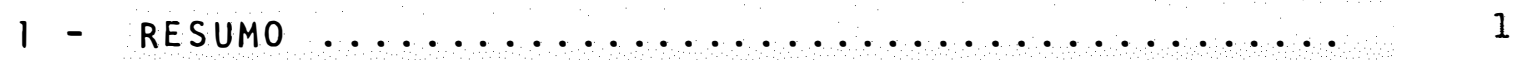

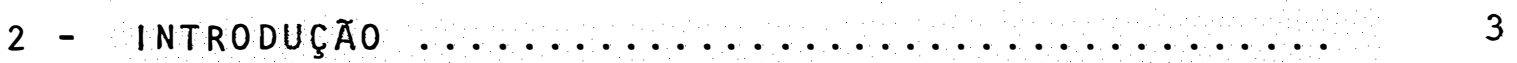

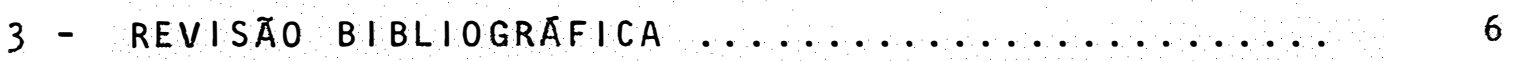

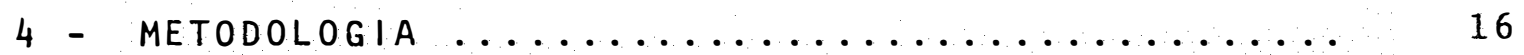

4.1 Local do Experimento .............. 16

4.2 - Análise Química do Solo ............. 17

4.3 - Delineamento Experimental .......... 18

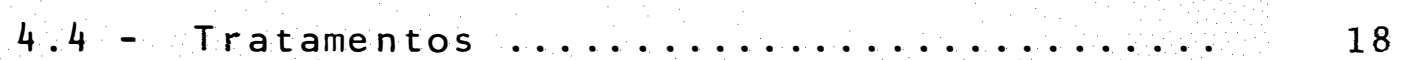

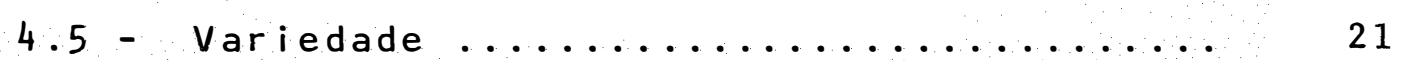



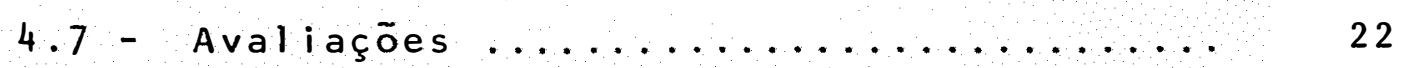

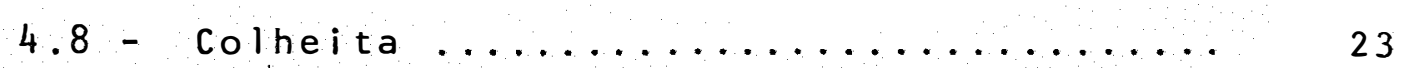



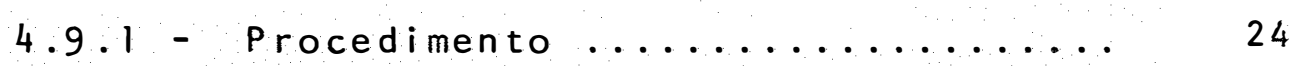

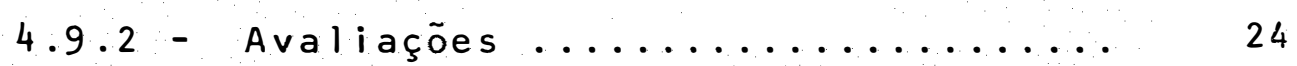



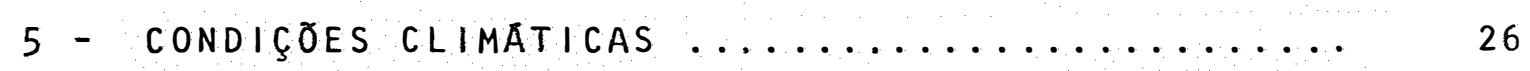

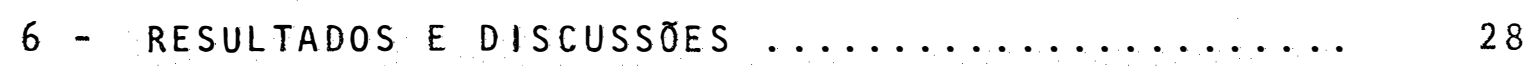

6.1 - Nümero de Perfilhos aos 90 Dias Após o

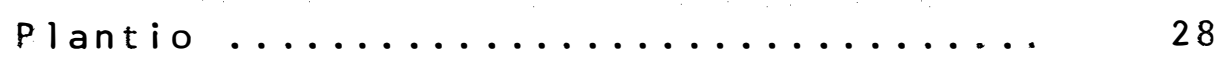


Pàgina

6.2 - Avaliação do Estadoinutricional da Ca-

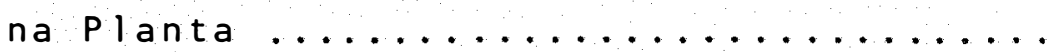

6.3 - Número de Colmos Industrializáveis por ocasião da Colheita e Peso Médio de Colmos ..................... 37

6.3 .1 - Cana planta ............... 37

6.3 .2 - Cana soca ................. 39

6.4 - Produtividade de Colmos da Cana Planta .. 41

6.5 - Produtividade de Pol em Cana Planta por Hectare .................. 43

6.6 - Qualidade Tecnológica da Cana-de-Açūcar.. 44

6.7 - Produtividade de Colmos e Pol da Cana Soca ......................... 45

6.8 - Qualidade Tecnológica da Cana Soca..... 48

6.9 - Produtividade Média de Dois Cortes para Colmos e Pol ................... 49

6.10 - Qualidade Tecnológica da Cana-de-Açúcar Representativa de Dois Cortes (Cana Plan

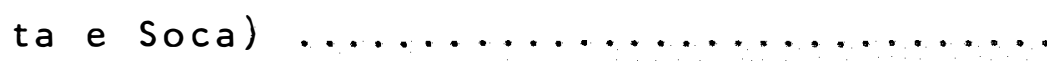

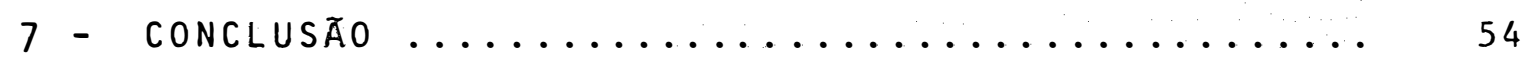

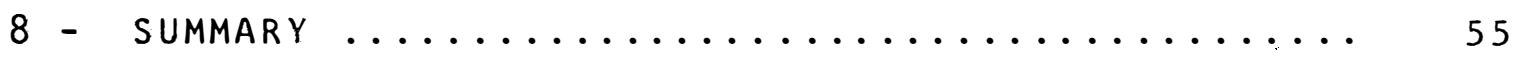

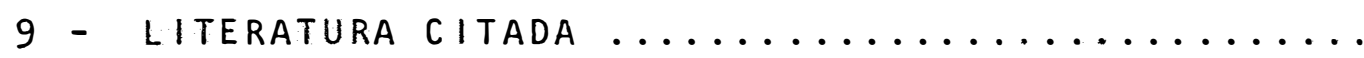


TABELA 1 - Composição química do solo LR obtida à profundidade de $0-40 \mathrm{~cm}$, antes do plan.

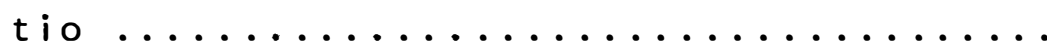

TABELA 2 - Composição química do silicato de cäl-

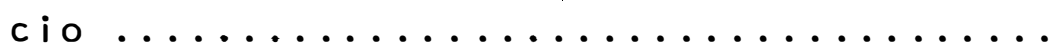

TABELA $3-\operatorname{Tratamentos} \ldots \ldots \ldots \ldots \ldots \ldots$

TABELA 4 - Precipitação pluviométrica mensal e total e temperatura média mensal para os anos de 1974,1975 e $1976 \ldots \ldots \ldots \ldots$

TABELA 5 - Número de perfilhos aos 90 dias apōs o

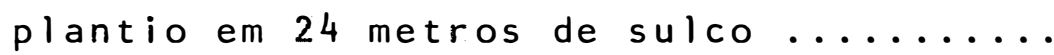

TABELA 6 - Teor de nutrientes na folha + 3 , em \% matēria seca, em outubro de 1974 , aos 6

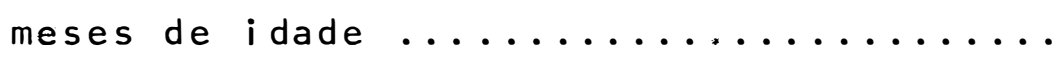

TABELA 7 - Teor de nutrientes na folha + 3 , em \% matéria seca, em janeiro de 1975, aos 9

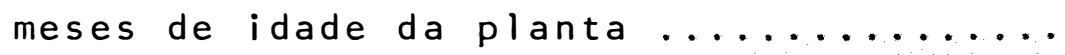

TABELA 8 - Teor de nutrientes na bainha + 3 , em \% matēria seca, em outubro de 1974 , aos 6

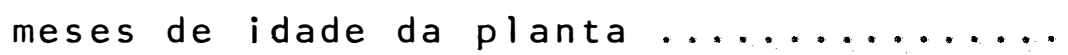

TABELA 9 - Teor de nutrientes na bainha + 3, em\% matēria seca, em janeiro de 1975, aos 9

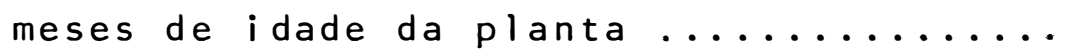


TABELA 10 - Teor de umidade na bainha +3 , aos 6 e 9 meses de idade da planta, em por-

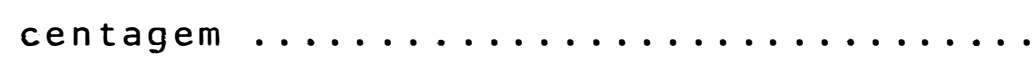

TABELA II - Nümero de colmos industrializáveis por hectare, e peso médio de colmo, na época da colheita, em cana planta com

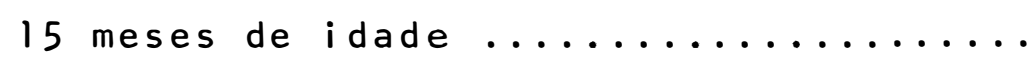

TABELA 12 - Número de colmos industrializáveis por hectare, e peso médio de colmo, na época da colheita, em cana soca, com 14

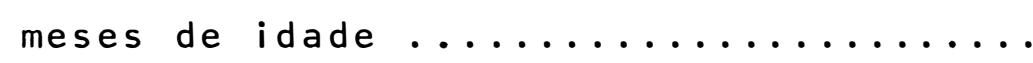

TABELA 13 - Produtividade de colmos e pol ( $t / h a$ ) em cana planta, aos 15 meses após o

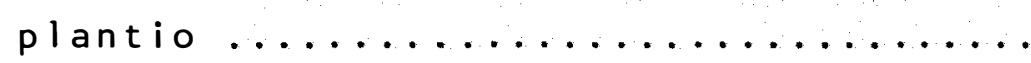

TABELA 14 - Valores médios de Brix, Pol e Fibra\%

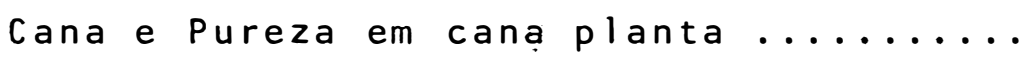

TABELA 15 - Produtividade de colmos e de pol

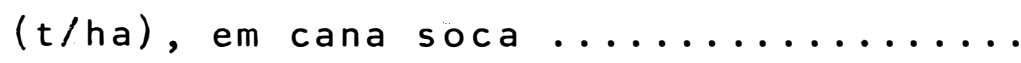

TABELA 16 - Valores médios de Brix, Pol e Fibra\%

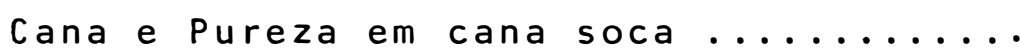

TABELA 17 - Produtividade de colmos e de pol (t/ha). Valores médios de dois cortes.

TABELA 18 - Valores médios de Brix, Pol e Fibra\% Cana e Pureza, representativos de dois




1 - RESUMO

Com o objetivo de estudar a influência da relação Silicio/Fósforo no estado nutricional, produtividade e quali dade tecnológica da cana-de-açūcar, como mais um fator de aumento de produtividade, foi conduzido um experimento com a va riedade CB 47-76, em solo pertencente ao grande grupo Latossol Roxo, na Estação Experimental de Cana Copersucar, município de Piracicaba, SP, Utilizando-se o delineamento estatístico de blocos casualizados com oito tratamentos e três repetições.

os efeitos dos tratamentos foram avaliados na cana planta através do nümero de perfilhos aos 90 dias; da anālise da folha e bainha +3 aos 6 e 9 meses de idade; do nūmero de colmos industrializáveis e peso médio de colmo; da produção de colmos e de pol e da anālise tecnológica da cana-deaçūcar. Na cana soca, a avaliação foi feita através da produ 
ção de colmos e de pol, e pela anālise tecnológica da cana-de -açūcar.

A adição de 3,0 t/ha de silicato de cálcio no plantio, na presença de $120 \mathrm{~kg} / \mathrm{ha}$ de $\mathrm{P}_{2}{ }_{5} / \mathrm{ha}$, ocasionou um aumen to de $6,4 \%$ na produtividade da cana planta e de $16 \%$ na produtividade da soqueira, não influindo praticamente na qualidade tecnológica da cana-de-açúcar como matéria prima industrial. 


\section{2 - INTRODUৎÃO}

A cultura de cana-de-açūcar constitui-se em impor tante fonte de divisas para o Brasil, destacando-o entre os principais produtores mundiais de açūcar e àlcool. Por outro lado a atual crise energética e a prioridade dada a o Programa Nacional do Alcool realça ainda mais a sua importáncia como fonte de energia, exigindo um aumento gradativo na quantidade de matēria prima a ser processada nos próximos anos. A prodú tividade média de cana-de-açúcar no Brasil está em torno de 50 toneladas por hectare, a qual pode ser considerada baixa, em relação a os demais países produtores de cana-de-açūcar.

0 aumento da ārea para produção de matéria prima vi sando atender o processamento está limitado a determinadas re giões, tornando-se necessārio portanto, aumentar a produtividade, o que a curto prazo parece ser a solução mais viāvel e econōmica. 
Dentre os fatores responsāveis pelo desenvolvimento vegetativo e produtividade da cana-de-açūcar a adubação apresenta-se como um dos limitantes, justificando desta forma todos os estudos relativos, que possam contribuir de alguma for ma para o aumento da produtividade.

Neste aspecto, os macro e micronutrientes tem sido estudados extensivamente no sentido de se obter a melhor adubação para a cana-de-açūcar nas diferentes condições. Além disso, o aproveitamento de resíduos da indústria açucareira e alcooleira tem apresentado bons resultados com relação ao aumento da produtividade e redução do custo de produção da cana-de-açūcar.

Embora o silicio não esteja relacionado entre os nu trientes considerados essenciais para o desenvolvimento normal da planta, é o maior constituinte mineral da maioria dos solos cultivados com cana-de-açūcar e de modo geral, o elemen to mais absorvido pela cultura. Os silicatos vem sendo utili zados há muitos anos em solos do Havai e de outros paises na adubação da cana-de-açūcar, e respostas à sua aplicação tem sido obtidas em diferentes espécies vegetais.

0s silicatos provavelmente desempenham uma função mūltipla na nutrição de plantas, como: solubiliza o fósforo do solo e favorece a sua absorção e utilização pela planta ; fornece cálcio e silício; diminui a acidez do solo; diminui os níveis tóxicos de elementos como Al, Fe e Mn, e outras 
funções especificas.

Assim, tendo em vista os aspectos mencionados, foi realizado este trabalho, com o objetivo de estudar a relação Silício/fósforo e sua influência no estado nutricional, produtividade e qualidade tecnológica da cana-de-açūcar, como mais um fator de aumento de produtividade. 


\section{3 - REVISÃO BIBLIOGRĀFICA}

0 silicio, um dos elementos ma is abundantes das cin zas das plantas tem recebido atenção especial nos ūitimos anos. Embora os fisiologistas não o considerem um elemento es sencial no contexto geral de nutrição de plantas, tem-se demonstrado experimentalmente que este elemento pode influenciar o desenvolvimento principalmente de gramineas, como a cana-de -açūcar.

A maior parte do silicio encontra-se nas plantas na forma inorgànica e pequena parte em combinação como proteína nas plantas superiores (Ozaki e Higashiro, citados por OKUDA e TAKAHASHI, 1964).

HUSZ (1972) relata que a função especîfica do sỉlicio nas plantas é pouco conhecida, mas que este elemento está presente na cana-de-açūcar em quantidades variāveis. Ainda que o silício seja normalmente abundante, alguns solos são deficien- 
tes. A aplicação de silicatos em solos do Havai é feita em quantidades maiores do que 7 toneladas por hectare.

Segundo OKUDA e TAKAHASHI (1964), o silicio é neces sário à cultura arroz pelas suas peculiaridades fisiológicas, atuando durante todo o período de desenvolvimento da planta e na formação do grão. LEWIN e REIMANN (1969) destacam a impor tância do silício nas plantas superiores através dos efeitos no desenvolvimento normal das plantas, na fertilidade do solo e na resistência ao ataque de pragas e doenças.

CLEMENTS (1967) constatou que a aplicação de silicio causou uma redução significativa de manganês na planta e admitiu que um dos efeitos do silicato consiste na redução dos efeitos tóxicos do manganès, cobre, ferro e de outros, Em a guns casos, a adubação com silicato de cálcio e o carbonato de cátcio são comparáveis. Entretanto, o efeito desejāvel pode não ser obtido se apenas a calagem é efetuada, devido a maior fixação do silício no solo, o que poderia sugerir que o silicio é um nutriente essencial para a planta com função especîfica.

Experimentos realizados por vārios pesquisadores (ALI, 1966 ; AYRES, 1966 ; FOX et alii, 1968) mostraram um au mento na absorção de silî́cio pelas várias espécies de plantas, com doses crescentes do elemento.

HALAIS e PARISH (1963) observaram, que a absorção de silício aplicado no solo está relacionada ao seu teor de óxidos de ferro e de aluminio. Embora as espécies sejam diferen 
tes na sua capacidade em absorver silício (OKUDA e TAKAHASHI, 1964), a quantidade de silício na solução do soloé a mesma encontrada na planta (FOX et alii, 1967).

Segundo AYRES (1966) a calagem com carbonato de cál cio, diminuindo a concentração de silīcio na solução do solo, reduz a absorção deste elemento pela cana-de-açūcar, Por outro lado, o silicato de cálcio foi responsável pelo aumento do pH do solo e diminuição da absorção de manganēs e alumỉnio. Este pesquisador propos que algum nivel minimo de disponibili dade de silicio no solo deve existir, o qual é essencial para o crescimento normal da cana-de-açūcar.

Outro: aspecto interessante relacionado ao comportamento do silicio, diz respeito ao fósforo no solo e na planta. Segundo KHAN e ROY (1964) o silício pode exercer algumas funções do $P$, inclusive substituí-lo parcialmente, discordando assim das observações de OKUDA e TAKAHASHI (1964) e LEWIN e REIMANN (1969).

DEWAN e HUNTER (1949) verificaram que a aplicação de silicato de sódio e magnésio aumentou o teor de $\mathrm{P}$ na soja, p $\underline{0}$ rēm, a absorção de $P$ foi aumentada somente em presença de baixas relações de $P$, concordando com as observações de RALEIGH (1953). Por outro lado, ROTHBUHR e SCOTT (1957) usando silicio radioativo, mostraram que a adição de $P$ reduz levemente a quantidade de silício absorvido pelo trigo, tendo o silicato a celerado a absorção do fósforo. Segundo os autores, existe uma estreita relação no metabolismo de silício e fósforo. 
ENGEL (1958) constatou um aumento na absorção de silício pelo trigo quando o silicato foi adicionado à solução nutritiva na presença de $P$.

CLEMENTS (1965) constatou uma diminuição na concentração de $P$ na cana-de-açūcar com a aplicação de silicato nos solos do Havaí, atribuindo-o ao efeito de diluição associado ao aumento no desenvolvimento da planta. De acordo como autor, as concentrações de $P$ na cana-de-açūcar, foram aumenta das pelas aplicações de silicato.

Ali, citado por RoY (1969) cultivando cana-de-açú car em vasos, observou um aumento na absorção de silício pela aplicação de silicato em solução sem fósforo. A adição de sí licato aumentou a disponibilidade de $P$ no solo, que sob condi ções de deficiência do elemento, seria acompanhado por aumento de produtividade. Constatou ainda o autor que, para con centrações semelhantes de P nas plantas, aquelas tratadas com silicato desenvolveram-se melhor, indicando que o silicio pro vavelmente melhora o aproveitamento de $P$ pela planta em decor rência da melhor utilização do P do solo. FISHER (1929) rela ta que os fertilizantes contendo silica podem aumentar a dis ponibilidade de fósforo no solo.

Segundo RoY (1969) a absorção de fósforo e silîcio pelas plantas cultivadas em solução nutritiva é função das es pécies, sendo que a presença de silicicio e fósforo acelerou a absorção de $P$ em alface e milho, inibindo-a em arroz e canade-açūcar. De modo geral, a presença de fósforo inibiu a ab 
sorção de silício pelas plantas, sendo esta inibição maior quando o fósforo e o silício foram fornecidos às plantas na mesma proporção.

RoY et alii (1971) constataram que aplicações de si licato tenderam a aumentar o teor de fósforo nas partes verdes e diminuir a sua concentração no colmo, na ausencia do elemento. 0 mesmo efeito foi tambēm observado em niveis inter mediārios de fósforo, não sendo verificado quando o nīvel de fósforo era alto. Estes dados, segundo os autores, sugerem que o silício acelera a mobilização de fósforo dos tecidos me nos ativos, quando o nível nutricional de fósforo é baixo. observaram ainda, que sem a adição de fósforo o silîcio aumentou visivelmente o perfilhamento, que geralmente está associa do com melhor nutrição de fósforo.

Segundo PLUCKNETT (1972), a aplicação de silicato au menta a solubilidade de fósforo no solo, diminui a fixação do fertilizante fosfatado, corrige as deficiencias de cálcio e magnésio e aumenta o pH do solo.

Com relação ao teor na planta, ROY (1969) constatou que as maiores concentrações de silicio foram encontradas nas folhas 2 e 3 , e em menor proporção no colmo da cana-de-açū car. Em todas as partes da planta, os efeitos da interação de fósforo e silício inibiram mais as concentrações destes ele mentos quando os mesmos foram fornecidos na mesma proporção.

Segundo BAIR (1966) o teor de silicio na folha foi mais elevado em plantas crescendo em solos de alta produtivi- 
dade do Havai e para algumas áreas de baixa produtividade 0 teor de silicio foi abaixo do nivel limitante de produção de cana-de-açūcar. FoX et alii (1968) sugerem que o silicio solúvel pode fornecer suficiente informação sobre o teor do ele mento na planta, sendo este maior na bainha que nas folhas de cana-de-açúcar. Constataram a inda que, embora os compostos so lúveis de silício em tecidos de cana-de-açūcar não sejam abun dantes, ele se encontra em maior concentração nos tecidos menos ativos metabolicamente e tambēm com elevado teor de fósfó ro.

Segundo MENGEL e KIRKBY (1978), os cereais e gramineas contém de 2 a $20 \mathrm{mg}$ de $\mathrm{Si} / \mathrm{g}$ de matéria seca,enquanto que as dicotiledóneas podem conter apenas um décimo desta quantidade ou menos. Em plantas ricas em silício, inclusive o arroz, as concentrações chegam a tē $100 \mathrm{mg} / \mathrm{g}$. Geralmente, tecidos mais velhos da planta contém maior teor de silicio do que os mais jovens.

De acordo com FoX et alii (1967), o teor de silica igua 1 a $0,70 \%$ é considerado adequado em cana-de-açūcar. Segundo GALLO et alii (1974), o teor médio de silicio em folhas de diferentes variedades de cana-de-açūcar foi de $1,51 \%$, ten do sido encontrado teores desde $1,03 \%$ a té $1,90 \%$.

0 efeito do silicio sobre o desenvolvimento da plan ta e sua produtividade foi constatado por vārios pesquisado res os quais verificaram que a aplicação de silicatos solúveis aceleram a formação de grãos de cereais (HALL e MORRISSON, 
1906) e aumentam a produção de cevada (BARNETTE, 1924).

Por outro lado, Brenchley et alii, citado por ALI (1966) observaram que a silica solúvel produziu um efeito sig nificativo no desenvolvimento vegetativo da cevada em solução deficiente de fósforo, enquanto que o teor de fósforo na plan ta diminui com a aplicação de silicato.

Totz, citado por ALI (1966) observou aumentos signi ficativos na produção de cevada e "sudan-grass" com a aplicação de silicato de cálcio e magnésio, sendo os mesmos maiores em presença de baixas doses de fósforo; o mesmo foi constatado por RAUPACK e PIPER (1959).

Experimentos realizados no Havai por FoX et ali $i$

(1967) mostraram que a fertilização com silício na cana-de-açūcar foi benéfica para determinados solos e os resultados até então obtidos foram assim resumidos:

- a produtividade pode ser aumentada pela aplicação de silício em solos com baixo teor de ácido silícico móvel;

- análise de solos pobres em silício (Latossois húmicos fer ruginosos) mostram relações positivas entre disponibilidade de silicio para a planta e o seu teor na cana-de-açūcar;

- os seguintes produtos apresentam bons resultados: silicato de cálcio e escórias de silicato de cálcio.

ROSS et alii (1974), estudando o efeito residual de doses crescentes de silicato de cálcio em duas variedades de 
cana-de-açūcar, constataram que ambas as variedades responderam igualmente bem à aplicação durante o ciclo. Em geral, a resposta foi inversamente proporcional ao teor de silicio no solo, sendo a maior resposta obtida em solo com o mais baixo teor de silicio ( $36 \mathrm{ppm}$ ) e a menor em solo com mais alto teor de silicio (105 ppm). Baseando-se em equaçoes de regressão ob tidas a partir dos dados de silicio na folha e no solo, os a $\underline{u}$ tores concluiram que houve um áumento na produção de cana-deaçūcar para os teores de silica na 3 ? folha,igual a $1,91 \%$ de $\mathrm{SiO}_{2}$, o que corresponderia a $116,0 \mathrm{ppm}$ de silicio no solo.

ROY (1969) observou que as produções de cana-de-açü car aumentaram proporcionalmente à aplicação de fósforo, enquanto que o silî́cio não aumentou a produção significativamen te, resultado este tambēm encontrado por BAIR (1966), na Fiórida.

Por outro lado, GASHO e ANDREIS (1974) constataram que o silicato de cálcio aumentou significativamente a produtividade de cana-de-açūcar, em solos da flórida, com os baixos níveis de silīcio solúvel em àgua. A resposta positiva foi constatada em doses acima de 17,8 toneladas por hectare pa ra solo arenoso, enquanto em solo orgānico a dose ótima foi inferior.

Segundo RAUPACK e PIPER (1959) a produtividade da cana-de-açūcar foi significativamente aumentada com a aplicação de silicatos em duas variedades de cana-de-açūcar, tendo os efeitos desaparecidos com a soqueira. A baixa produção de ca 
na-de-açūcar foi melhorada pela aplicação de 7 a 14 toneladas de silicato de cálcio/ha no plantio, com efeito residual nos do is cortes consecutivos (CHEONG, 1970).

Em Mauritius, D'HOTMAN DE VILLIERS(1961) constatou que solos corrigidos com silicatos a umentaram a produtividade da cana-de-açūcar. Por outro 1ado, HALAIS e PARISH (1963) ve rificaram que a silica solūvel foi especificamente responsável pelo aumento na produtividade da cana-de-açúcar.

Segundo Gaussman, citado por JONES e HANDRECK (1967) o aumento no fornecimento de fósforo produz aumentos sistemáticos na produção de matéria seca, acompanhado pela diminui ção de concentração da silica nas plantas.

HURNEY (1974) trabalhando com cana-de-açūcar, obteve aumentos de produção devido à aplicação de silicatos em so los de Queensland. Observou a inda que o teor de açūcar na ca na diminui com o aumento de produção, resultando porém em uma maior produção de açūcar por área, tendo os efeitos sido semelhantes na cana planta e soqueiras. 0 autor associou a res posta da cana-de-açūcar à aplicação de silīcio nos solos estú dados, ao aumento na elongação do colmo e ào precoce "fecha mento" das plantas.

Em Taiwan, SHIUE (1964) observou que os solos pobres em $\mathrm{SiO}_{2}$ solúvel apresentaram baixa produtividade de cana-de-a çūcar e que os solos arenosos são mais pobres em $\mathrm{siO}_{2}$ solúvel que os solos salinos de mesma textura. 
CLEMENTS (1965) e AYRES (1966) demonstraram que o silicato de cálcio melhora a qualidade da cana-de-açūcar, bem como a sua produtividade. AYRES (1966) encontrou um aumento de 7,2 toneladas de açūcar por hectare em relação à testemu nha com a aplicação de 12 toneladas de escória de silicato de cālcio por hectare. CLEMENTS (1965) obteve um aumento significativo na produção de pol, com a adição de silicato de sódio que tambēm foi atribuido ao aumento na qualidade da canade-açūcar.

FOX et alii (1967) obtiveram aumentos da ordem de 13,4 toneladas na pol por hectare com a aplicação de 5 tonela das de silicato de cālcio por hectare.

Finalmente, a aplicação de 11,2 toneladas de silica to de cálcio aumentou a produção de açūcar em 7 toneladas por hectare, quando comparada com tratamentos que não receberam 0 produto, enquanto que o carbonato de cálcio mostrou uma ten dência a reduzir a produção de açūcar (SHERMAN, 1969). 
4 - METODOLOGIA

As informaçōes obtidas na revisão bibliogrāfica resultaram na instalação de um experimento de campo, apresentan do as seguintes caracteristicas:

4.7 - Local do Experimento

0 experimento foi instalado em abril de 1974, na Es tação Experimental da Copersucar, em Piracicaba, Estado de São Paulo, utilizando-se um solo caracterizado como pertencente ao grande grupo Latossol Roxo, homogēneo e de topografia plana, cultivado com cana-de-açūcar hā vārios anos. 
4.2 - Anälise Química do Solo.

A composição quîmica do solo obtida à profundidade de $0-40 \mathrm{~cm}$, antes do plantio da cana, encontra-se na Tabela 1.

TABELA 1 - Composição quīmica do solo LR obtida à profundidade de $0-40 \mathrm{~cm}$ antes do plantio

\begin{tabular}{lc}
\hline Elementos & Teor \\
\hline Acidez (pH) & 5,35 \\
Matéria Orgänica (\%) & 1,30 \\
$* \mathrm{PO}_{4}^{--}$ & 0,07 \\
$* \mathrm{~K}^{+}$ & 0,07 \\
$* \mathrm{Ca}^{++}$ & 3,00 \\
$* \mathrm{Mg}^{++}$ & 1,10 \\
$* \mathrm{H}^{+}$ & 6,40 \\
$* \mathrm{Al}^{+++}$ & 0,15 \\
$* \mathrm{CTC}$ & 10,57 \\
$* * \mathrm{Si}$ & 20,80 \\
\hline (*) emg/100 ml de TFSA & $(* *) \mathrm{em} \mathrm{ppm}$
\end{tabular}

0 pH foi determinado utilizando-se a relação solol āgua igual a $1: 2,5$. 0 carbono orgānico foi determinado pe 10 método de Walkely-Black, descrito por JACKSON (1958), e pa ra obter a porcentagem de matéria orgānica,multiplicou-se a porcentagem de carbono orgānico por 1,724. O fósforo solú- 
vel, potāssio, hidrogēnio e o aluminnio trocāveis, pelos métodos descritos por CATANI et alii (1955). A capacidade de tro ca cationica foi calculada somando-se as bases trocáveis. 0 cālcio e o magnésio pelo método do EDTA, segundo GLORIA et alii (1965). O silīcio do solo foi extraído com àcido sulfūrico, densidade de 1,47 , e o seu teor foi determinado pelo método colorimétrico do molibdato de amōnio (VETTORI, 1969).

4.3 - Delineamento Experimental

Foi utilizado o delineamento experimental de blocos casualizados com oito tratamentos e trēs repetições, segundo GOMES (1970). Cada parcela foi constituída por cinco sulcos de 8 metros de comprimento, espaçados de 1,5 metros. 0s blocos foram separados entre si por carreadores de 2 metros, 0 mesmo acontecendo com as bordaduras de frente, fundo e laterais.

A ārea útil de cada parcela foi constituída pelos trés sulcos centrais, ocupando uma ārea de $36 \mathrm{~m}^{2}$.

\section{4 - Tratamentos}

Tendo em vista os objetivos propostos neste experimento, foram estabelecidos os seguintes tratamentos: 
1 - Tes temunha absoluta

$2-N P_{0} K S i_{0}$

$3-\mathrm{N}_{0} \mathrm{P}_{1} \mathrm{~K}_{0} \mathrm{Si}_{0}$

$4-N P_{1} K S_{0}$

5 - N $P_{0} K+$ silicato de cálcio

6 - N $P_{1} K+$ silicato de cálcio

7 - N $P_{0} K+$ calcārio dolomítico

8 - $N P_{1} K+$ calcário dolomitico

0 silicato de cálcio (Tabela 2) foi aplicado na dosagem de três toneladas por hectare. 0 cálcio e o magnésio, aplicados com o silicato de cálcio, foram incluídos nos trata mentos para eliminar o efeito desses elementos, tendo-se em pregado o calcário dolomítico na dosagem de duas toneladas por hectare, contendo $28,8 \%$ de $\mathrm{CaO}$ e $14,5 \%$ de $\mathrm{MgO}$.

TABELA 2 - Composição química do silicato de câlcio *

Elementos

Anidrido silicico $\left(\mathrm{SiO}_{2}\right)$

oxido de cálcio (CaO)

oxido de magnésio (MgO)

Umidade
$\%$

43,2

19,2

6,9

5,0

(*) Determinado pelo Instituto de Pesquisas Tecnológicas (IPT), conforme certificado no 407.198. 
0 nitrogénio e o potássio foram aplicados nas dosagens de 60 e $120 \mathrm{~kg} / \mathrm{ha}$, respectivamente na forma de sulfato de amônio e cloreto de potássio, e o fósforo na quantidade de $120 \mathrm{~kg} / \mathrm{ha}$ na forma de superfosfato triplo (Tabela 3 ).

TABELA 3 - Tratamentos

\begin{tabular}{|c|c|c|c|c|c|c|c|}
\hline \multirow{2}{*}{\multicolumn{2}{|c|}{ Tratamentos }} & \multicolumn{4}{|c|}{ Doses de Nutrientes } & \multicolumn{2}{|c|}{$(\mathrm{kg} / \mathrm{ha})$} \\
\hline & & N & $P_{2} O_{5}$ & $\mathrm{~K}_{2} \mathrm{O}$ & $\mathrm{CaO}$ & MgO & $\mathrm{SiO}_{2}$ \\
\hline 1 & - Tes temunha & & & & & & \\
\hline & $-N P_{0} K S_{0}$ & 60 & & 120 & & & \\
\hline & $-\mathrm{N}_{0} \mathrm{P}_{1} \mathrm{~K}_{0} \mathrm{Si}_{0}$ & & 120 & & & & \\
\hline & $-N P_{1} K S_{0}$ & 60 & 120 & 120 & & & \\
\hline 5 & $-N P_{0} K S_{1}$ & 60 & & 120 & 580 & 206 & 1.300 \\
\hline & $-N P_{1} K S i_{1}$ & 60 & 120 & 120 & 580 & 206 & 1.300 \\
\hline & $-\mathrm{NP}_{0} \mathrm{KCa}+\mathrm{Mg}$ & 60 & & 120 & 580 & 290 & \\
\hline & $-\mathrm{NP}_{1} \mathrm{KCa}+\mathrm{Mg}$ & 60 & 120 & 120 & 580 & 290 & \\
\hline
\end{tabular}

As dosagens aplicadas para $\mathrm{N}, \mathrm{K}_{2} \mathrm{O}$ e $\mathrm{P}_{2} \mathrm{O}_{5}$ são recomendadas para a adubação de plantio da cana-de-açúcar no Esta do de São Paulo (Guimaräs, 1974). 


\section{5 - Variedade.}

A variedade utilizada no experimento foi a CB 41-76 tendo sido escolhida por encontrar-se entre as mais cultiva das no Estado de São Paulo.

Esta variedade apresenta as seguintes caracteristicas agroindustriais (BASSINELLO et alii, 1976): relativamente exigente em água e fertilidade; boa produtividade agrícola; acentuado tombamento; despalha facilmente; usualmente

não floresce; apresenta uma porcentagem mēdia de fibra; boa brotação de soqueira e resistencia ao mosaico. E uma varieda de média quanto ao teor de sacarose.

\section{6 - Instalação e Condução.}

o preparo do solo para plantio constou de duas arações e duas gradagens!, seguindo-se a demarcação da ārea para sulcação.

os fertilizantes minerais foram colocados no fundo do sulco de plantio em dose total, com exceção do nitrogênio, que foi parcelado, sendo $1 / 3$ no plantio e $2 / 3$ em cobertura após 180 dias.

0 plantio de cana-de-açúcar foi efetuado em abril de 1974 utilizando-se mudas sadias com 12 meses de idade, pro venientes de viveiros pré tratados termicamente. 
Foram plantadas 12 gemas por metro linear de sulco, utilizando-se toletes de 3 gemas, os quais foram tratados previamente com solução de Benlate a 0,05\% durante 10 minutos, com o objetivo de prevenir falhas de brotação causadas por fun gos do solo e do tolete. Os podões utilizados no corte dos to letes foram desinfetados previamente em solução de Lysoform a $5 \%$. Os sulcos de plantio foram polvilhados com Aldrin a $5 \%$ na dosagem de $40 \mathrm{~kg} / \mathrm{ha}$, como medida preventiva contra ataque de pragas do solo.

Os tratos culturais da cana planta, feitos com o ob jetivo de manter a cultura livre da concorrência de ervas daninhas, constaram de três cultivos, sendo um mecānico e dois manuais.

\section{$4.7-\underline{\text { Avaliações }}$}

- Nūmero de perfilhos existentes nos três sulcos centrais de cada parcela aos 90 dias após o plantio;

- Amostragem de 10 folhas + 3 com as respectivas bainhas considerando-se a primeira com aurícola visivel a +1 de acordo com o sistema de Kuijper, segundo VAN DILLEWIJN (1952), aos 6 e 9 meses após o plantio, em outubro/74 e janeiro/75 respectivamente, para avaliação do estado nutricional da planta visando estudar a relação $\mathrm{P} / \mathrm{Si}$ na mesma. Foram efetuadas determinações de $\mathrm{N}$, 
$\mathrm{P}, \mathrm{K}, \mathrm{Ca}, \mathrm{Mg}$ e Si no terço central da follha e na ba $\mathrm{i}$ nha de acordo com a técnica proposta por SARRUGE e HAAG (1974). As bainhas foram usadas também para a determina ção de umidade;

- Produção de colmos, em toneladas por hectare, obtida através do peso dos colmos colhidos nos trés sulcos cen trais de 8 metros, correspondentes a uma área de $36 \mathrm{~m}^{2}$;

- Anālise tecnológica da cana-de-açúcar efetuada na época da colheita, em amostras compostas por 15 colmos coletados seguidamente no sulco central de cada parcela. Foram efetuadas determinações de Brix, Pol e Fibra \% cana pelo método da prensa hidráulica (TANIMOTO, 1964).

A pureza refratométrica foi calculada a partir dos dados de brix e pol \% cana;

- Produção de pol, em t/ha, calculada em função dos dados de produção de colmos e pol \% cane.

- Número de colmos industrializáveis por ocasião da colhei ta e peso médio de colmo.

$4.8-$ Colheita

A cana-de-açūcar foi colhida aos 15 meses de idade, através de corte manual e despalha pelo fogo. A pesagem dos trés sulcos centrais de cada parcela, considerada para produtividade foi feita no campo com dinamómetro (marca kratos) de pesagem fixada em engate de trés pontos de um trator. 


\section{9 - Soqueira}

Com o objetivo de avaliar o efeito residual do fós foro e silicato na cana-de-açúcar foram conduzidos estudos na soqueira de lo corte.

\subsection{1-Procedimento}

Após a colheita, procedeu-se ao enleiramento da paTha utilizando-se ancinho enleirador, seguindo-se a adubação da soqueira que constou da aplicação de $340 \mathrm{~kg} / \mathrm{ha}$ da fórmula $18-00-36$, correspondendo dessa maneira ao fornecimento de $6.0 \mathrm{~kg}$ de nitrogēnio $(N)$ e $120 \mathrm{~kg}$ de potássio $\left(K_{2} 0\right)$ feitos seguindo-se a metodologia tradicional para a cana-de-açūcar, cons tando de um cultivo mecānico logo após a adubação e outro aos 90 dias de idade da soqueira.

A colheita da cana soca foi efetuada aos 14 meses de idade, sendo empregada a mesma metodologia para a cana plan ta.

\section{9 .2 - Avaliações}

- Produção de colmos e de pol, em toneladas por hectare,pe sando-se os colmos colnidos em três sulcos de 8 metros;

- Número de colmos industrializáveis por ocasião da colhei ta e peso médio de colmo; 
- Qualidade tecnológica da cana-de-açūcar medida através das determinações de Brix, Pol e Fibra \% Cana, pelo método da prensa (TANIMOTo, 1964) e cálculo da pureza. A amostragem também foi feita seguindo-se o mesmo procedimento adotado para cana planta.

\subsection{0- Anālises Estatísticas}

Os dados obtidos para cana planta,durante o período de desenvolvimento e por ocasião da colheita e,para cana soca, na colheita, foram submetidos à anālise estatistica de acordo com o delineamento estabelecido. A análise estatística foi efetuada na Escola Superior de Agricultura "Luiz de Queiroz", obedecendo-se o seguinte esquema para anālise da variān cia:

\begin{tabular}{lc}
\hline Causa da Variação & G. L. \\
\hline Blocos & 2 \\
Tratamentos & 7 \\
Resĩduo & 14 \\
\hline Total & 23 \\
\hline
\end{tabular}

A comparação das médias foi feita pelo teste de Tukey, obtendo-se desta forma a diferença mínima significativa. 


\section{5 - CONDIGÕES CLIMĀTICAS}

A precipitação pluviométrica mensal e total durante o decorrer do experimento,incluindo-se a cana planta e soque $i$ ra, para os anos de 1974,1975 e 1976 e os dados mensais e anuais de temperatura (māxima e minnima) registrados no mesmo periodo, encontram-se na Tabela 4 .

A precipitação total ocorrida durante o ciclo da ca na planta $(09 / 04 / 74$ a $24 / 07 / 75)$ e na soqueira $(24 / 07 / 75$ a 02/09/76) estā incluîda tambēm na Tabela 4 . 


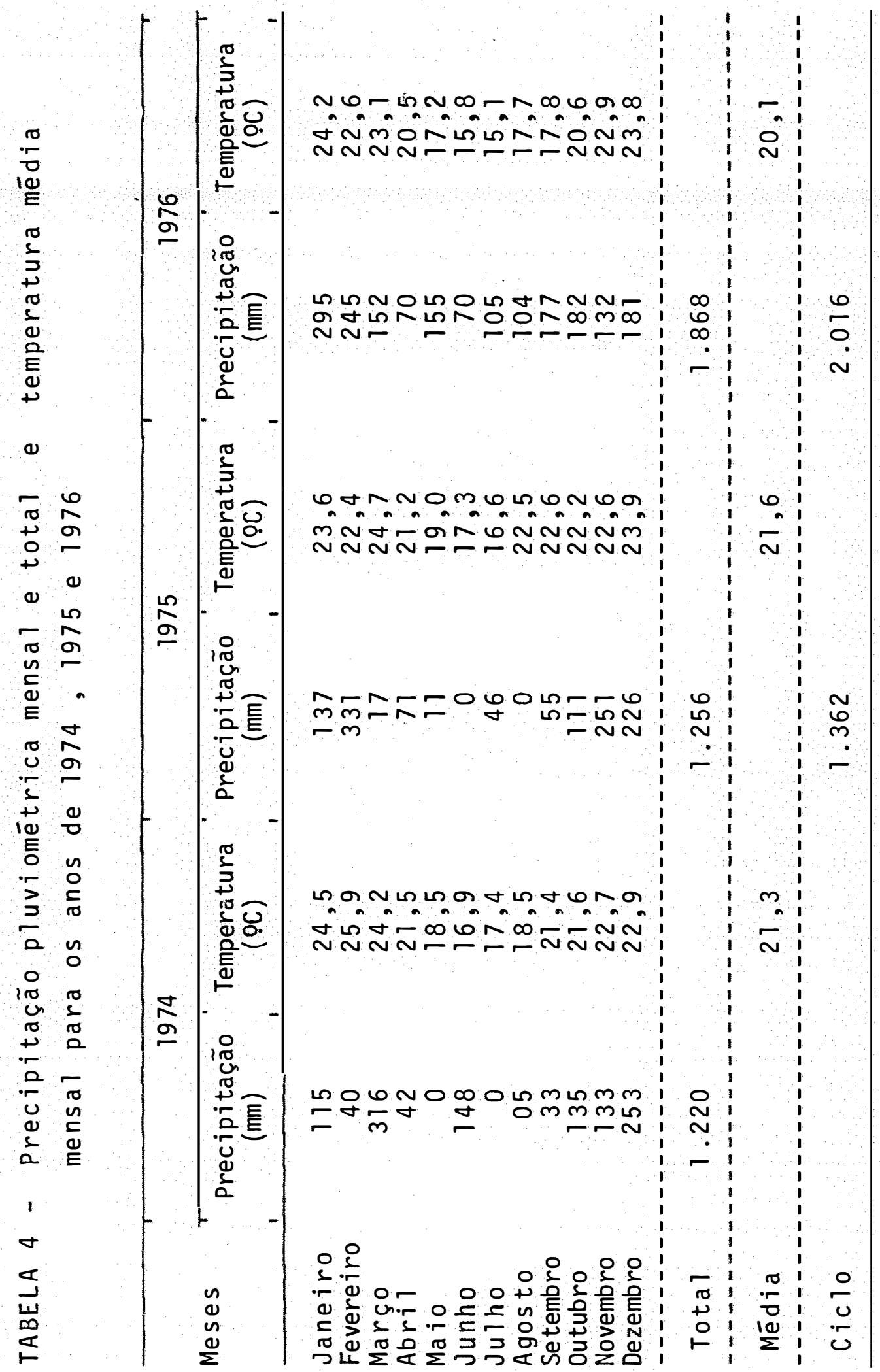




\section{6 - RESULTADOS E DISCUSSÕES}

6.1 - Número de Perfilhos aos 90 Dias Após o Plantio

A avaliação do perfilhamento na cana planta aos: 90 dias apōs o plantio, feita nos trés sulcos centrais de cada parcela (Tabela 5), indicou uma baixa porcentagem de perfilhos, aproximadamente $30 \%$, o que pode ser explicada, provavelmente, pela ocorréncia de baixa precipitação por ocasião do plantio e logo apōs o mesmo (Tabela 4).

A anālise da variāncia mostrou que os tratamentos di feriram significativamente entre si, indicando um efeito destes no perfilhamento da cana-de-açūcar. A comparação das médias pelo teste de Tukey mostra que o tratamento $\mathrm{N}_{0} \mathrm{KSi}_{1}$, foi significativamente menor que os demais tratamentos (Tabela 5). Observa-se que o menor nūmero de perfilhos ocorreu na ausēncia de fósforo e na presença de silicato, contrariando as 
sim as observações feitas por ROY et alii (1971) e aquelas de KHAN e ROY (1964). O maior nūmero foi observado na presença de NPK e calcārio dolomitico, indicando assim um melhor com portamento do fósforo associado ao cālcio e magnésio, na cana planta.

TABELA 5 - Número de perfilhos aos 90 dias apōs o plantio em 24 metros de sulco

\begin{tabular}{|c|c|c|}
\hline \multicolumn{2}{|c|}{ Tratamentos } & Nümero de perfilhos por $24 \mathrm{~m}$ \\
\hline \multicolumn{2}{|c|}{ Tes temunha } & 99 \\
\hline$N \quad P_{0} K$ & $\mathrm{Si}_{0}$ & 108 \\
\hline$N_{0} P_{1} K_{0}$ & $\mathrm{Si}_{0}$ & 113 \\
\hline $\begin{array}{lll}N & P_{1} & K\end{array}$ & $\mathrm{Si}_{0}$ & 179 \\
\hline$N \quad P_{0} K$ & $\mathrm{Si}_{7}$ & 91 \\
\hline $\begin{array}{lll}N & P_{1} & K\end{array}$ & $\mathrm{Si}_{1}$ & 114 \\
\hline $\begin{array}{lll}N & P_{0} & K\end{array}$ & $\mathrm{Ca}+\mathrm{Mg}$ & 108 \\
\hline $\begin{array}{lll}N & P_{1} & K\end{array}$ & $\mathrm{Ca}+\mathrm{Mg}$ & 125 \\
\hline \multicolumn{2}{|l|}{$\mathrm{F}$} & $5,24 * *$ \\
\hline \multicolumn{2}{|l|}{ dms $(5 \%)$} & 6,6 \\
\hline \multicolumn{2}{|l|}{ C.V. $(\%)$} & 2,1 \\
\hline
\end{tabular}

(**) Significativo ao nível de $1 \%$ de probabilidade 
6.2 - Avaliação do Estado Nutricional da Cana Planta.

A avaliação do estado nutricional da cana planta feita aos 6 e 9 meses de idade, atravēs da anālise da folna +3 e bainha +3 (Tabelas 6 a 9), não mostrou qualquer rela ção entre os teores de nutrientes na planta e a adubação da cana-de-açūcar nas idades mencionadas, não tendo a anālise de variāncia apresentado qualquer diferença significativa entre os tratamentos.

TABELA 6 - Teor de nutrientes na folna + 3 , em matéria seca, em outubro de 1974 , aos 6 meses de idade

\begin{tabular}{|c|c|c|c|c|c|c|}
\hline \multirow{2}{*}{ Tratamentos } & \multicolumn{6}{|c|}{$\%$ Matéria Seca } \\
\hline & N & $P$ & $\mathrm{~K}$ & $\mathrm{Ca}$ & $\mathrm{Mg}$ & Si \\
\hline Tes temunha & 2,12 & 0,19 & 1,01 & 0,63 & 0,14 & 0,59 \\
\hline $\mathrm{N} \mathrm{P} \mathrm{KS} \mathrm{Si}_{0}$ & 2,18 & 0,19 & 1,24 & 0,54 & 0,13 & 0,51 \\
\hline $\mathrm{N}_{0} \mathrm{P}_{1} \mathrm{~K}_{0} \mathrm{Si}_{0}$ & 2,07 & 0,20 & 1,09 & 0,64 & 0,16 & 0,54 \\
\hline $\mathrm{NP}, \mathrm{KSi}_{0}$ & 2,10 & 0,19 & 1,25 & 0,58 & 0,15 & 0,52 \\
\hline$N P_{0} K S i_{1}$ & 2,23 & 0,20 & 1,09 & 0,66 & 0,15 & 0,56 \\
\hline$N P_{1} K S_{1}$ & 2,26 & 0,19 & 1,12 & 0,62 & 0,15 & 0,56 \\
\hline $\mathrm{N} \mathrm{P}_{0} \mathrm{KCa}+\mathrm{Mg}$ & 2.15 & 0,19 & 1,15 & 0,56 & 0,12 & 0,50 \\
\hline $\mathrm{N} \mathrm{P} \mathrm{P}_{1} \mathrm{KCa}+\mathrm{Mg}$ & 2,26 & 0,20 & 1,22 & 0,58 & 0,14 & 0,51 \\
\hline-------- & & --- & --- & --- & --- & ---- \\
\hline$F$ & 2,58 & 0,78 & 0,47 & 0,71 & 0,43 & 1,80 \\
\hline $\mathrm{dms}(5 \%)$ & 0,22 & 0,04 & 0,62 & 0,25 & 0,10 & 0,12 \\
\hline C.V. $(\%)$ & 3,58 & 7,12 & 18,76 & 14,41 & 23,40 & 7,98 \\
\hline
\end{tabular}


TABELA 7 - Teor de nutrientes na Folha + 3 , em \% matéria seca, em janeiro de 1975 , aos 9 meses de idade da planta

\begin{tabular}{|c|c|c|c|c|c|c|}
\hline \multirow{2}{*}{ Tratamentos } & \multicolumn{6}{|c|}{ \% Matéria Seca } \\
\hline & $N$ & $P$ & $k$ & $\mathrm{Ca}$ & $\mathrm{Mg}$ & Si \\
\hline Tes temunha & 2,44 & 0,21 & 1,64 & 0,48 & 0,16 & 0,60 \\
\hline$N P_{0} K S i_{0}$ & 2,45 & 0,22 & 1,33 & 0,52 & 0,17 & 0,72 \\
\hline $\mathrm{N}_{0} \mathrm{P}_{1} \mathrm{~K}_{0} \mathrm{Si} \mathrm{i}_{0}$ & 2,45 & 0,21 & 1,17 & 0,55 & 0,19 & 0,71 \\
\hline$N P_{1} K S i_{0}$ & 2,19 & 0,21 & 1,50 & 0,47 & 0,16 & 0,68 \\
\hline$N P_{0} K S_{1}$ & 2,37 & 0,22 & 1,12 & 0,52 & 0,19 & 0,68 \\
\hline $\mathrm{N} \mathrm{P} \mathrm{P}_{1} \mathrm{KSi}$ & 2,32 & 0,22 & 1,35 & 0,54 & 0,17 & 0,72 \\
\hline $\mathrm{N} \mathrm{P}_{0} \mathrm{KCa}+\mathrm{Mg}$ & 2,31 & 0,22 & 1,38 & 0,53 & 0,19 & 0,62 \\
\hline $\mathrm{NP} \mathrm{P}_{1} \mathrm{KCa}+\mathrm{Mg}$ & 2,31 & 0,21 & 1,43 & 0,46 & 0,18 & 0,71 \\
\hline $\mathrm{F}$ & 0,85 & 0,33 & 1,04 & 0,86 & 0,72 & 1,45 \\
\hline $\operatorname{dms}(5 \%)$ & 0,50 & 0,05 & 0,83 & 0,18 & 0,08 & 0,19 \\
\hline C.V. (\%) & 7,36 & 8,40 & 21,07 & 12,22 & 15,21 & 9,52 \\
\hline
\end{tabular}


TABELA 8 - Teor de nutrientes na bainha +3 , em $\%$ matéria seca, em outubro de 1974 , a os 6 meses de idade da planta

\begin{tabular}{|c|c|c|c|c|c|c|}
\hline \multirow{2}{*}{ Tratamentos } & \multicolumn{6}{|c|}{ \% Matēria Seca } \\
\hline & $N$ & $P$ & $k$ & $\mathrm{Ca}$ & $\mathrm{Mg}$ & Si \\
\hline Testemunha & 0,66 & 0,08 & 1,92 & 0,38 & 0,20 & 0,51 \\
\hline $\mathrm{N} \mathrm{P}_{0} \mathrm{~K} \mathrm{Si}_{0}$ & 0,72 & 0,09 & 2,69 & 0,37 & 0,20 & 0,47 \\
\hline $\mathrm{N}_{0} \mathrm{P}_{1} \mathrm{~K}_{0} \mathrm{Si} \mathrm{i}_{0}$ & 0,70 & 0,09 & 1,96 & 0,38 & 0,24 & 0,48 \\
\hline$N P_{1} K S i_{0}$ & 0,69 & 0,08 & 2,59 & 0,38 & 0,20 & 0,45 。 \\
\hline $\mathrm{NP}_{0} \mathrm{~K} \mathrm{Si}_{1}$ & 0,75 & 0,10 & 2,33 & 0,42 & 0,22 & 0,52 \\
\hline N. $\mathrm{P}_{1} \mathrm{~K} \mathrm{Si}$ & 0,66 & 0,09 & 2,32 & 0,41 & 0,21 & 0,48 \\
\hline $\mathrm{N} \mathrm{P} \mathrm{P}_{0} \mathrm{KCa}+\mathrm{Mg}$ & 0,69 & 0,08 & 2,53 & 0,32 & 0,19 & 0,38 \\
\hline $\mathrm{N} \mathrm{P} \mathrm{P}_{1} \mathrm{Ca}+\mathrm{Mg}$ & 0,68 & 0,09 & 2,54 & 0,33 & 0,20 & 0,50 \\
\hline$F$ & 2,49 & 1,19 & 0,96 & 1,15 & 0,52 & 5,95 \\
\hline $\mathrm{dms}(5 \%)$ & 0,09 & 0,03 & 1,46 & 0,16 & 0,71 & 0,09 \\
\hline C.V. $(\%)$ & 4,70 & 10,76 & 21,49 & 14,40 & 19,24 & 6,61 \\
\hline
\end{tabular}

$\left({ }^{* *}\right)$ Significativo ao nīvel de $1 \%$ de probabilidade 
TABELA 9 - Teor de nutrientes na bainha + 3 , em $\%$ matéria seca, em janeiro de 1975 , aos 9 meses de idade da planta

\begin{tabular}{|c|c|c|c|c|c|c|}
\hline \multirow{2}{*}{ Tratamentos } & \multicolumn{6}{|c|}{ \% Matēria Seca } \\
\hline & N & $P$ & K & $\mathrm{Ca}$ & $\mathrm{Mg}$ & $\mathrm{Si}$ \\
\hline Testemunha & 0,67 & 0,09 & 1,78 & 0,37 & 0,20 & 0,81 \\
\hline$N \mathrm{P}_{0} \mathrm{~K} \mathrm{Si}_{0}$ & 0,65 & 0,09 & 1,88 & 0,36 & 0,21 & 0,74 \\
\hline $\mathrm{N}_{0} \mathrm{P}_{1} \mathrm{~K}_{0} \mathrm{Si}$ & 0,67 & 0,09 & 1,81 & 0,33 & 0,23 & 0,76 \\
\hline $\mathrm{N} \mathrm{P} \mathrm{KS}_{0}$ & 0,64 & 0,09 & 1,39 & 0,36 & 0,20 & 0,93 \\
\hline $\mathrm{N} \mathrm{P}_{0} \mathrm{~K} \mathrm{Si}_{7}$ & 0,69 & 0,09 & 1,87 & 0,40 & 0,22 & 0,67 \\
\hline N. $\mathrm{P}_{1} \mathrm{~K} \mathrm{Si}_{1}$ & 0,63 & 0,08 & 1,88 & 0,38 & 0,19 & 0,67 . \\
\hline $\mathrm{N} \mathrm{P}_{0} \mathrm{KCa}+\mathrm{Mg}$ & 0,69 & 0,09 & 2,05 & 0,37 & 0,20 & 0,80 \\
\hline $\mathrm{NP} \mathrm{P}_{7} \mathrm{KCa}+\mathrm{Mg}$ & 0,64 & 0,09 & 1,85 & 0,38 & 0,20 & 0,69 \\
\hline 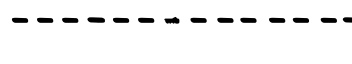 & & & & & & 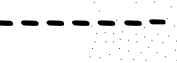 \\
\hline $\mathrm{F}$ & 0,54 & 0,26 & 0,51 & 0,70 & 0,56 & 18,39 \\
\hline dms $\quad(5 \%)$ & 0,13 & 0,03 & 1,31 & 0,12 & 0,07 & 0,10 \\
\hline C.V. $(\%)$ & 7,00 & 11,10 & 25,08 & 11,01 & 12,34 & 4,62 \\
\hline
\end{tabular}

(**) Significativo ao nível de $1 \%$ de probabilidade 
A anālise dos dados mostra que a adição de silicato no solo promoveu um aumento do teor de silicio na folha +3 , não alterando o teor de fósforo. Por outro lado, o teor de silicio na folha +3 mostrou uma tendencia a diminuir com a adição de fósforo,principalmente aos 9 meses de idade da cultura (Tabe la 7 ), quando os teores de nutrientes na folha + 3 foram ma $\underline{0}$ res que aos 6 meses de idade (Tabela 6 ). Por outro lado, a relação Si/P aos 6 meses de idade, aumentou aproximadamente $7 \%$ quando o silicato foi aplicado na presença de fósforo, enquan to que aos 9 meses esta relação manteve-se praticamente da mes ma ordem, quando comparados os tratamentos com e sem silicato na presença do fósforo.

De modo geral, os teores de silicio encontrados na folha + 3 estão abaixo daquele considerado adequado para cana-de-açūcar por FoX et alii (1967) e daquele encontrado por GALLO et alii (1974).

A avaliação do estado nutricional através da anālise da bainha + 3 também não apresentou relação com a adubação da cana-de-açūcar, tendo a anālise da variāncia mostrado uma diferença significativa entre os tratamentos apenas para o teor de silicato. Analisando a relação Si/P na planta aos 6 meses de idade (Tabela 8), observa-se que na ausēncia de silicato, e na presença de cālcio + magnēsio, a adição de fósforo provo cou um aumento no teor de silicio, na bainha +3 , resultado 
não constatado aos 9 meses de idade (Tabela 9), quando o opos to foi observado, tornando difícil qualquer generalização.

Em termos de relação Si/P na bainha +3 , verificase que houve uma queda na mesma quando comparados os tratamen tos com e sem o silicato, sendo a relação Si/P maior com o elemento que foi aplicado na presença do fósforo, tanto aos 6 meses como aos 9 meses de idade.

Pelos dados de umidade encontrados aos 6 e 9 meses de idade (Tabela 10), verifica-se que a mesma não foi limi tante para o estado nutricional da cultura, de acordo com SAMUELS (1969).

Assim, pelos dados obtidos, verifica-se que a anāli se da folha e bainha +3 não permitiu por si uma avaliação da relação Si/P na planta, devido às variações encontradas, o que vem confirmar as observações de ORLANDO FILHO (1976) segundo - qual a folha + 3 parece não ser a mais adequada para se ava liar o estado nutricional da cana-de-açūcar. 
TABELA 10 - Teor de umidade na bainha + 3, a os 6 e 9 meses de idade da planta, em porcentagem

\begin{tabular}{|c|c|c|}
\hline \multirow{2}{*}{ Tratamentos } & \multicolumn{2}{|c|}{ Umidade \% bainha } \\
\hline & 6 meses & 9 meses \\
\hline Tes temunha & 82,5 & 81,8 \\
\hline$N P_{0} K S i_{0}$ & 84,3 & 82,6 \\
\hline $\mathrm{N}_{0} \mathrm{P}_{1} \mathrm{~K}_{0} \mathrm{~S} \mathrm{i}_{0}$ & 82,1 & 81,1 \\
\hline$N P_{1} K S_{0}$ & 83,5 & 82,2 \\
\hline $\mathrm{N} \mathrm{P}_{0} \mathrm{KSi_{1 }}$ & 84,0 & 82,4 \\
\hline$N P_{1} K S_{1}$ & 83,8 & 81,9 \\
\hline $\mathrm{N} \mathrm{P}_{0} \mathrm{KCa}+\mathrm{Mg}$ & 84,0 & 82,1 \\
\hline $\mathrm{N} \mathrm{P}_{7} \mathrm{KCa}+\mathrm{Mg}$ & 83,7 & 81,9 \\
\hline---------- & ------ & ------ \\
\hline $\mathrm{F}$ & 2,49 & 1,33 \\
\hline dms $(5 \%)$ & 2,43 & 1,93 \\
\hline C.V. ( (\%) & 1,01 & 0,82 \\
\hline
\end{tabular}




\section{3 - Número de Colmos Industrializáveis por Ocasião da Colheita e Peso Médio de Colmos}

\section{3 .1 - Cana planta.}

Os dados obtidos para nümero de colmos industrializáveis por hectare e peso médio de colmo por ocasião da coTheita encontram-se na Tabela 11.

De modo geral, o número de colmos industrializáveis não foi afetado significativamente pelos tratamentos, enquanto que o peso médio de colmo apresentou diferença entre os mes mos. Observa-se pelo teste de Tukey, que o peso médio de colmo da testemunha foi significativamente menor que o do tratamento $N P_{1} K S_{i}$, enquanto que aquele na auséncia de $N$ e $K$ foi significativamente menor que os dos tratamentos $N P_{0} K S_{i}$, $N P_{1} K S_{i}$ e $N P_{1} K C a+M g$, os quais não diferiram entre si e dos demais.

Entretanto, a añ̄ise dos dados obtidos indicam um efeito positivo do silicato quando se compara os tratamentos com e sem o elemento na presença do $P$, com um peso médio 9,5\% superior na presença de Si. 0 oposto foi observado para o nū mero de colmos industrializáveis, sendo estes $2,9 \%$ menores na presença do silicato, o que resultaria, mesmo assim, em aumen to da produtividade da cana-de-açúcar. 
TABELA 11 - Nūmero de colmos industrializáveis por hectare, e peso médio de colmo, na época da colheita, em cana planita com 15 meses de idade

\begin{tabular}{|c|c|c|}
\hline Tratamentos & $\begin{array}{c}\text { Número de colmos in- } \\
\text { dustrializaveis por } \\
\text { hectare }\end{array}$ & $\begin{array}{c}\text { Peso médio de col } \\
\text { mo }(\mathrm{kg})\end{array}$ \\
\hline Tes temunha & 60.168 & 1,29 \\
\hline$N P_{0} K^{S i}{ }_{0}$ & 61.094 & 1,33 \\
\hline $\mathrm{N}_{0} \mathrm{P}, \mathrm{K}_{0} \mathrm{Si}_{0}$ & 66.648 & 1,22 \\
\hline$N P_{1} K^{S i_{0}}$ & 66.648 & 1,48 \\
\hline${ }^{N} P_{0} K S_{1}$ & 59.243 & 1,54 \\
\hline $\mathrm{N} \mathrm{P}_{1} \mathrm{~K} \mathrm{Si}$ & 69.796 & 1,62 \\
\hline $\mathrm{N} \mathrm{P}_{0} \mathrm{KCa}+\mathrm{Mg}$ & 62.020 & 1,41 \\
\hline $\mathrm{N} \mathrm{P}_{1} \mathrm{KCa}+\mathrm{Mg}$ & 66.648 & 1,54 \\
\hline----------- & ------------------ & $\cdots-\cdots-\cdots-1$ \\
\hline$F$ & 2,72 & $5,51 * \star$ \\
\hline $\mathrm{dms}(5 \%)$ & 9.462 & 0,28 \\
\hline$C . V .(\%)$ & 5,18 & 6,77 \\
\hline
\end{tabular}

$(* *)$ Significativo ao nivel de $1 \%$ de probabilidade

Na ausência de fósforo, o aumento no peso médio dos colmos com a aplicação do silicato foi $6,9 \%$, indicando assim um melhor efeito do silicato na presença de fósforo. 0 núme ro de colmos industrializáveis foi $3 \%$ menor. Com relação ao calcário dolomítico, verifica-se que a sua adição no solo re- 
sultou na produção de colmos com menor peso médio em compara ção à adição de silicato.

\section{3 .2 - Cana soca}

Resultados semelhantes aqueles constatados na cana planta foram obtidos também para a soqueira (Tabela 12), tendo sido constatada diferença significativa entre os tratamentos apenas para o peso médio de colmo. Neste caso, o tratamento sem $N$ e $K$, apresentou peso médio de colmo significativamente menor do que aqueles obtidos na presença de silicato e cálcio + magnésio, enquanto que a testemunha foi significativamente menor que o tratamento $N \mathrm{P}_{0} K \mathrm{Si}_{0}$ e aqueles contendo silicato ( $\mathrm{P}_{0} \mathrm{KSi} \mathrm{Si}_{1}$ e $\mathrm{N} \mathrm{P}_{1} \mathrm{~K} \mathrm{Si}_{1}$ ).

Entretanto, analisando-se os dados obtidos com a adição de silicato na presença de fósforo no plantio, verifica-se que houve um aumento de $15,9 \%$ no peso médio de colmos da soqueira, enquanto que o número de colmos industrializáveis por hectare se manteve da mesma ordem, evidenciando também o efeito residual do silicato de cálcio na soqueira.

$\mathrm{Na}$ ausēncia daquele elemento, a aplicação de $3,0 \mathrm{t}$ de silicato de cálcio no plantio, praticamente não influiu no peso médio de colmos da soqueira. 
Com relação ao calcārio dolomitico,verifica-se que a sua aplicação no solo ocasionou um maior número de colmos po rém com menor peso médio por colmo, em relação ao silicato de cālcio.

TABELA 12 - Nūmero de colmos industrializāveis por hectare e peso médio de colmo na época da colheita, em cana soca, com 14 meses de idade

\begin{tabular}{|c|c|c|c|}
\hline Tratamentos & $\begin{array}{c}\text { Nūmero de colmos } \\
\text { dustrializāveis } \\
\text { ha }\end{array}$ & $\begin{array}{l}\text { in- } \\
\text { por }\end{array}$ & $\begin{array}{c}\text { Peso médio } \\
\text { de colmo } \\
(\mathrm{kg})\end{array}$ \\
\hline Testemunha & 68.036 & & 0,97 \\
\hline$N \mathrm{P}_{0} \mathrm{~K} \mathrm{Si}_{0}$ & 75.442 & & 1,21 \\
\hline $\mathrm{N}_{0} \mathrm{P}_{1} \mathrm{~K}_{0} \mathrm{Si}_{0}$ & 76.367 & & 0,85 \\
\hline$N \mathrm{P}_{1} \mathrm{~K} \mathrm{Si}_{0}$ & 76.367 & & 1,07 \\
\hline $\mathrm{N} \mathrm{P}_{0} \mathrm{KSi}_{1}$ & 73.590 & & 1,23 \\
\hline$N P_{1} K S i_{1}$ & 76.367 & & 1,24 \\
\hline$N P_{0} \mathrm{~K} C a+M g$ & 78.219 & & 1,18 \\
\hline $\mathrm{NP} \mathrm{P}_{1} \mathrm{Ka}+\mathrm{Mg}$ & 78.219 & & 1,15 \\
\hline$F$ & 1,02 & & $8,04 * *$ \\
\hline dms $\quad(5 \%)$ & 16.344 & & 0,24 \\
\hline C.V. $(\%)$ & 7,53 & & 7,62 \\
\hline
\end{tabular}

$\left({ }^{*}\right)$ Significativo ao nível de $1 \%$ de probabilidade 
6.4 - Produtividade de Colmos da Cana Planta.

Os valores médios de produtividade de colmos da cana-de-açūcar, em toneladas por hectare, aos 15 meses de idade da cultura, por ocasião da. colheita, encontra-se na Tabela 13.

TABELA 13 - Produtividade de colmos e pol ( $t / h a$ ) em cana planta, aos 15 meses após o plantio

\begin{tabular}{|c|c|c|c|c|}
\hline \multirow{2}{*}{ Tratamentos } & \multicolumn{4}{|c|}{ Produtividade $\quad(t / h a)$} \\
\hline & Cana & $\%$ & Pol & $\%$ \\
\hline Tes temunha & 83,0 & 100 & 10,3 & 100 \\
\hline$N P_{0} K S i_{0}$ & 94,3 & 114 & 11,3 & 110 \\
\hline $\mathrm{N}_{0} \mathrm{P}_{1} \mathrm{~K}_{0} \mathrm{Si}_{0}$ & 87,0 & 105 & 12,2 & 118 \\
\hline$N P_{1} K S_{0}$ & 105,6 & 127 & 12,8 & 124 \\
\hline$N P_{0} K S_{1}$ & 97,3 & 117 & 10,5 & 102 \\
\hline$N P_{1} K S_{1}$ & 112,4 & 135 & 14,1 & 137 \\
\hline$N P_{0} K \mathrm{Ca}+\mathrm{Mg}$ & 93,3 & 112 & 10,8 & 105 \\
\hline $\mathrm{N} \mathrm{P}_{1} \mathrm{KCa}+\mathrm{Mg}$ & 109,7 & 132 & 12,9 & 125 \\
\hline $\begin{array}{c}\mathrm{F} \\
-\cdots \cdots \\
-\cdots\end{array}$ & 4.88 & $\star \star$ & 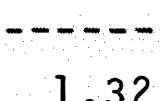 & \\
\hline $\mathrm{dms}(5 \%)$ & 23,9 & & 5,8 & \\
\hline C.V. $(\%)$ & 8,5 & & 16,9 & \\
\hline
\end{tabular}

(**) Significativo ao nivel de $1 \%$ de probabilidade. 
A análise da variancia dos dados obtidos mostra que houve diferença significativa entre os tratamentos estudados, tendo-se constatado uma resposta da cana-de-açūcar à aplica ção de fósforo, com as maiores produtividades sendo obtidas na presença deste elemento.

A comparação das médias pelo teste de Tukey mostra que a produtividade da tes temunha foi significativamente menor que a dos tratamentos $N P_{1} K S_{1}$ e N $P_{1} K C_{a}+M g, n a ̃ o d i-$ ferindo dos demais. Por outro lado, o tratamento $\mathrm{N}_{1} \mathrm{KS}_{\mathrm{I}}$, foi significativamente maior que $0 \mathrm{~N}_{0} \mathrm{P}_{1} \mathrm{~K}_{0} \mathrm{Si}_{0}$, o qual não diferiu dos demais tratamentos.

Entretanto, pela anālise dos dados,observa-se que a produtividade obtida na ausēncia de fósforo e presença de silicato foi $8,5 \%$ menor que aquela encontrada na presença de fós foro e ausencia de silicato. A aplicação de silicato de cálcio na ausência de fósforo ( $N P_{0} K S i_{1}$ ) praticamente não influiu na produtividade da cana-de-açúcar, acarretando um aumento de apenas $3 \%$ em relação ao tratamento sem silicato ( $N \mathrm{P}_{0} \mathrm{KSi}_{0}$ ), contrariando assim as observações de KHAN e ROY (1964) e concordando com os resultados encontrados por RAUPACK e PIPER (1959).

Verifica-se ainda que na presença de silicato, a adição de fósforo provocou um a umento na produtividade da ordem de $16 \%$, enquanto que na ausēncia de silicato,o fósforo acar retou um aumento de aproximadamente $12 \%$, indicando assim um 
pequeno efeito do silicato associado ao fósforo.

Por outro lado, a adição de fósforo na presença de cálcio + magnésio proporcionou um aumento de $18 \%$, denotando as sim uma maior eficiēncia do fósforo na cana planta quando as sociado aqueles elementos aplicados na forma de calcário dolo mitico.

Na presença de fósforo, a aplicação de trés toneladas de silicato de cálcio promoveu um aumento de $6,4 \%$ na produtividade da cana-de-açücar, concordando assim com os resultados tambem encontrados por CHEONG (1970) e HURNEY (1974).

\section{5 - Produtividade de Pol em Cana Planta}

A anālise de variāncia dos dados permite observar que a produtividade de pol/ha não foi afetada significativa mente pelos diferentes tratamentos. Entretanto, os valores mé dios da Tabela 13, mostram que a aplicação de silicato na pre sença de fósforo proporcionou um acréscimo de $10 \%$ na pol/ha, enquanto que na auséncia daquele elemento houve um decréscimo da ordem de $7,6 \%$, denotando assim a importāncia da relação Si/P na produtividade de pol da cana-de-açúcar. Resultados se melhantes foram obtidos também por AYRES (1966), FOX et alii (1967) e SHERMAN (1969). 
.6.6 - Qualidade Tecnológica da Cana-de-Açūcar

Os valores médios de Brix, Pol e Fibra \% Cana e Pu reza, na cana planta, com 15 meses de idade, nos diferentes tratamentos, encontram-se na Tabela 14

TABELA 14 - Valores médios de Brix, Pol e Fibra \% Cana e Pureza em cana planta

\begin{tabular}{|c|c|c|c|c|}
\hline Tratamentos & Brix \% Cana & Pol \% Cana & Pureza & Fibra \% Cana \\
\hline Testemunha & 16,0 & 12,2 & 75,5 & 11,6 \\
\hline$N P_{0} K S i_{0}$ & 16,3 & 12,1 & 73,7 & 10,5 \\
\hline $\mathrm{N}_{0} \mathrm{P} \quad \mathrm{K}_{0} \mathrm{Si}_{0}$ & 17,3 & 14,0 & 81,3 & 11,7 \\
\hline$N P_{1} K S_{0}$ & $15, T$ & 12,1 & 76,7 & 11,3 \\
\hline $\mathrm{N} \mathrm{P}_{0} \mathrm{~K} \mathrm{Si}_{1}$ & 15,0 & 10,8 & 71,5 & 10,9 \\
\hline $\mathrm{N} \mathrm{P}_{1} \mathrm{~K} \mathrm{Si}$ & 15,8 & 12,5 & 79,2 & 11,2 \\
\hline $\mathrm{N} \mathrm{P}_{0} \mathrm{~K} \mathrm{Ca}+\mathrm{Mg}$ & 15,5 & 11,6 & 74,8 & 11,1 \\
\hline $\mathrm{N} \mathrm{P}{ }_{1} \mathrm{KCa}+\mathrm{Mg}$ & 15,8 & 11,7 & 74,1 & 11,3 \\
\hline $\mathrm{F}$ & 1,46 & 1,25 & 1,09 & 1,12 \\
\hline $\mathrm{dms} \quad(5 \%)$ & 2,7 & 4,2 & 15,0 & 1,7 \\
\hline C.V. $(\%)$ & 5,1 & 9,6 & 6,9 & 5,3 \\
\hline
\end{tabular}


Embora a anālise da variāncia não tenha acusado diferença significativa entre os tratamentos, verifica-se que de modo geral, a aṕlicação de silicato proporcionou um aumento de $3,3 \%$ na pol \% cana,quando aplicado na presença de fósforo. Por outro lado,á aplicação de fósforo na presença de silicato acarretou uma elevação de $16 \%$ na pol \% cana o que constitui um importante fator do ponto de vista industrial.

6.7 - Produtividade de Colmos e de Pol da Cana Soca

A Tabela 15 apresenta os dados médios de produtividade para cana soca aos 14 meses de idade, tendo os tratamentos diferido significativamente entre si, de acordo com a ana lise da variāncia.

Pelo teste de Tukey, verifica-se que a testemunha e o tratamento $\mathrm{N}_{0} \mathrm{P}_{1} \mathrm{~K}_{0} \mathrm{Si}_{0}$ apresentaram uma produtividade significativamente menor que todos os tratamentos, com exceção do $N P_{1} K S_{0}$, o qual não diferiu dos demais.

Entretanto, analisando os dados obtidos, observa-se que houve um efeito residual da aplicação de fósforo no plantio e uma melhor resposta a silicato na soqueira, em relação à cana planta, contrariando assim as observações de RAUPACK e PIPER (1959), porém semelhante aos resultados obtidos por CHEONG (1970). A produtividade da soqueira,pela aplicação de silicato na presença de fósforo no plantio, foi da ordem de 16 : 
maior que aquela obtida na auséncia do elemento, enquanto que na ausēncia do fósforo a adição de silicato no plantio não pro moveu qualquer efeito na produtividade da soqueira, com resul tado semelhante ao encontrado na cana planta.

TABELA 15 - Produtividade de colmos e de pol ( $t / h a)$, em cana soca

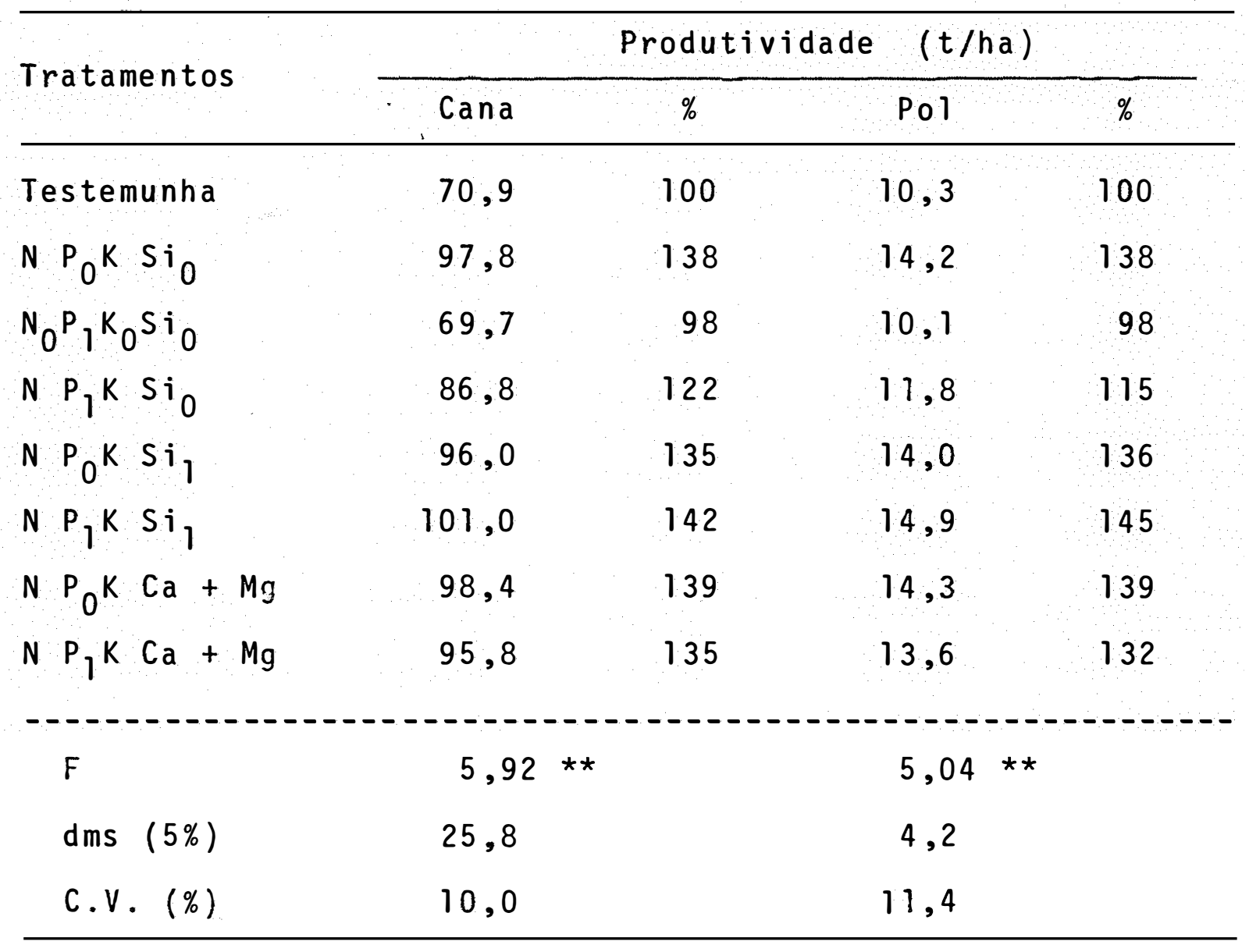

(**) Significativo ao nível de $1 \%$ de probabilidade 
A aplicação de fósforo na presença de silicato, por ocasião do plantio, acarretou um acréscimo na produtividade da soqueira menor que o encontrado na cana planta (5\%), indicando assim o pequeno efeito residual do fósforo na soqueira.

Comparando-se os tratamentos com silicato (N $P_{1} K$ $\mathrm{Si}_{1}$ ) e calcārio dolomītico (N $\mathrm{P}_{1} \mathrm{~K} \mathrm{Ca}+\mathrm{Mg}$ ) na presença do fós foro, verifica-se que aquele apresentou uma produtividade $5,4 \%$ maior, denotando assim o melhor comportamento do silicato de cālcio na soqueira de cana-de-açūcar.

Em relação à testemunha, obteve-se um aumento de $22,0 \%$ na presença de fósforo e ausēncia de silicato e $42,0 \%$ na presença de ambos os elementos, indicando também um efeito residual do silicato na soqueira da cana-de-açūcar.

Com relação a produtividade de pol/ha, a anālise de variância mostrou haver uma diferença significativa entre os tratamentos, tendo os dados obtidos, apresentado um compor camento semelhante ao da produtividade de cana por estarem di retamente relacionados a esse parámetro.

A pol / ha da soqueira, obtida na presença de fósforo e silicato, foi significativamente maior que a dos trata mentos $\mathrm{N}_{0} \mathrm{P}_{1} \mathrm{~K}_{0} \mathrm{Si}_{0}$ e testemunha, não diferindo dos demais.

Entretanto, a produtividade de pol / ha obtida com a aplicação de silicato na presença de fósforo ( $P_{1} K S i_{1}$ ) foi $26 \%$ maior em relação à observada sem a adição de silicato $\left(N P_{1} K S i_{0}\right)$. Este resultado indica um melhor aproveitamen- 
to do silicato na soqueira em relação à cana planta, fato tam bém constatado para a produtividade da cana. Quando este ele mento foi aplicado na ausência do fósforo não se obteve qualquer efeito na produtividade de pol na soqueira.

6.8 - Qualidade Tecnológica da Cana Soca.

o comportamento tecnológico da cana soca foi seme -

lhante ao da cana planta do ponto de vista estatistico, não tendo sido constatado qualquer diferença significativa entre os tratamentos estudados. De modo geral, os valores obtidos na cana soca, aos 14 meses de idade,foram mais elevados que os da cana planta (Tabela 16). 
TABELA 16 - Valores médios de Brix, Pol e Fibra \% Cana e Pureza em cana soca

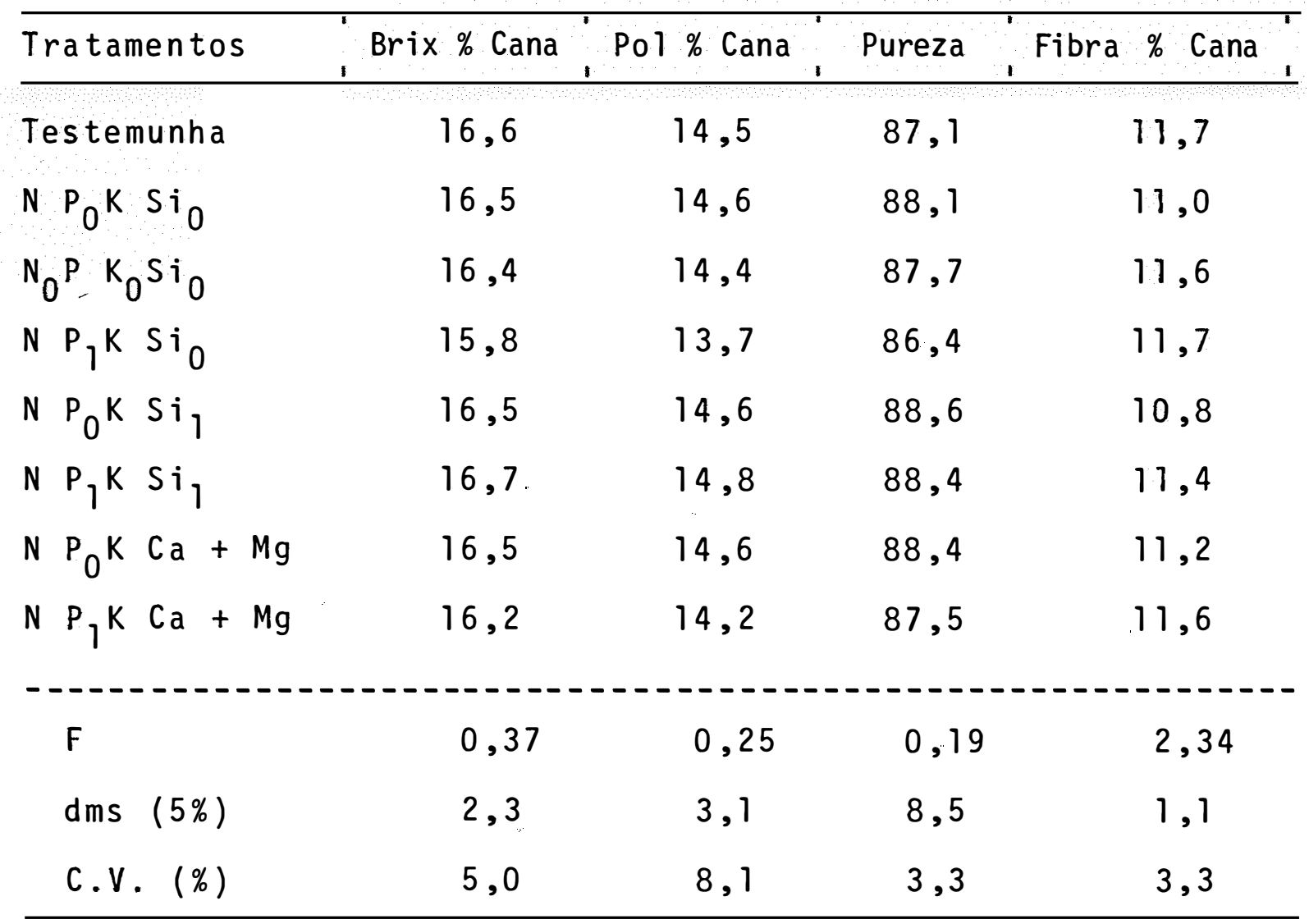

6.9 - Produtividade Média de Dois Cortes para Colmos e Pol

A anālise conjunta dos dois ciclos (Tabela 17), evi dencia um efeito significativo dos tratamentos sobre a produtividade de cana e de pol por hectare, sendo que os tratamen tos contendo $P$ ou $S i$ foram significativamente melhores que a testemunha, não diferindo entre si. Por outro lado, a produ- 
tividade obtida na presença de $\mathrm{P}$ e $\mathrm{Si}$, e $\mathrm{P}+\mathrm{Ca}+\mathrm{Mg}$, foram $\mathrm{su}$ periores àquela onde. o nitrogénio e o potássio foram omitidos mesmo na presença de fósforo.

TABELA 17 - Produtividade de colmos e de pol ( $t / h a)$. Valores médios de dois cortes



$\left({ }^{*}\right)$ Significativo ao nivel de $1 \%$ de probabilidade 
Comparando-se os tratamentos $\mathrm{NP}_{1} \mathrm{KS}_{0} \mathrm{eN} \mathrm{P}_{1} \mathrm{~K} \mathrm{Si}_{1}$ verifica-se que este apresentou uma produtividade $11 \%$ maior que o primeiro, denotando desta forma um efeito positivo da aplica ção de silicato na presença de fósforo, o mesmo não acontecendo na auséncia deste elemento.

Quando o fósforo foi adicionado na presença do silicato ( $\mathrm{N}_{1} \mathrm{KSi}_{1}$ ) obteve-se uma produtividade de 10 toneladas a mais que na auséncia do elemento ( $\left.N P_{0} K S i_{1}\right)$, o mesmo acon tecendo em relação a cálcio + Magnésio, com um acréscimo de 7 toneladas.

$\mathrm{Na}$ ausēncia do fósforo, a aplicação de silicato de cálcio e calcário dolomítico a presentaram produtividades seme lhantes, enquanto que na presença de fósforo a aplicação de silicato foi mais eficiente que a de calcário sobre a produti vidade da cana-de-açūcar.

Para pol/ha, as mesmas observações são válidas do ponto de vista prático, não tendo sido constatada qualquer di ferença significativa entre os tratamentos. Entretanto, tendo em vista o aumento da pol/ha em função da aplicação de silicato, infere-se que este elemento pode ser empregado para me lhorar a produtividade da cana-de-açūcar. 
6.10 - Qualidade Tecnológica da Cana-de-Açúcar Representativa de Dois Cortes (Cana Planta e Soca)

Os valores médios de Brix, Pol e Fibra \% Cana e Pureza, representativos de dois cortes, encontram-se na Tabela 18.

TABELA 18 - Valores mēdios de Brix, Pol e Fibra \% Cana e Pureza, representativos de dois cortes

\begin{tabular}{|c|c|c|c|c|}
\hline Tratamentos & Brix \% Cana & Pol \% Cana & Pureza & Fibra \% cana \\
\hline Tes tem unha & 16,3 & 13,3 & 81,3 & 11,7 \\
\hline$N \mathrm{P}_{0} \mathrm{~K} S \mathrm{i}_{0}$ & 16,4 & 13,3 & 80,9 & 10,8 \\
\hline $\mathrm{N}_{0} \mathrm{P}_{1} \mathrm{~K}_{0} \mathrm{Si}$ & 16,8 & 14,2 & 84,5 & 11,6 \\
\hline$N P_{1} K S_{0}$ & 15,8 & 12,9 & 81,5 & 11,5 \\
\hline $\mathrm{N} \mathrm{P}_{0} \mathrm{~K} \mathrm{Si}_{1}$ & 15,8 & 12,7 & 80,0 & 10,9 \\
\hline $\mathrm{N} \mathrm{P} \mathrm{P}_{1} \mathrm{~K} \mathrm{Si}_{1}$ & 16,3 & 13,6 & 83,3 & 11,3 \\
\hline $\mathrm{N} \mathrm{P}_{\mathrm{O}} \mathrm{K} \mathrm{Ca}+\mathrm{Mg}$ & 16,0 & 13,1 & 81,6 & 17,2 \\
\hline $\mathrm{N} \mathrm{P}_{1} \mathrm{KCa}+\mathrm{Mg}$ & 16,0 & 13,0 & 80,8 & 11,4 \\
\hline $\mathrm{F}$ & 2,73 & 0,58 & 0,61 & 2,26 \\
\hline dms $(5 \%)$ & 2,1 & 1,8 & 9,9 & 1,5 \\
\hline C.V. $(\%)$ & 6,5 & 3,2 & 5,9 & 4,7 \\
\hline
\end{tabular}


Pela anālise da variāncia, verifica-se que os trata mentos não diferiram entre si como foi constatado isoladamente para cana planta e soqueira. Entretanto, verifica-se que a pol \% cana na presença de silicato e de N P K (N P $1 K \mathrm{Si}_{1}$ ). foi $5,4 \%$ maior que aquela obtida na auséncia daquele elemento, indicando assim uma pequena influência do elemento na pol \% ca na, o que está de acordo com CLEMENTS (1965) e AYRES (1966). 


\section{7 - CONCLUSÃO}

A aplicação de 3,0 toneladas de silicato de cálcio por hectare no plantio, na presença de $120 \mathrm{~kg}$ de $\mathrm{P}_{2} \mathrm{O}_{5} / \mathrm{ha}$, oca sionou um aumento de $6,4 \%$ na produtividade da cana planta e de $16 \%$ na produtividade da soqueira, não influindo praticamen te na qualidade da cana-de-açūcar como matéria prima industrial. 


\section{8 - SUMMARY}

The object of this research was to study the influence of silicon-phosphorus rations on the nutrition, production, and industrial quality of sugarcane using on experiment with 8 treatments and three replications in a randomized block design with CB 41-76 on a red latosol at the Copersucar Expe riment Station at Piracicaba, SP. The effect of the treatments in plant cane were evaluated by incidence of tillering at 90 days, analyses of leaf and sheath samples $(+3)$ at 6 and 9 months, and number, weight and quality of millable canes. In the ratoon the effect of treatments were evaluated by number, weight and quality of millable canes.

The results indicated that application of calcium silicate at the rate of 3 tons per ha and phosphate at $120 \mathrm{~kg}$ 
$\mathrm{P}_{2} \mathrm{O}_{5}$ per ha applied in the plant crop gave an increase in pro duction of $6.4 \%$ in the plant crop and $16 \%$ in the ratoon.

There was no significant effect on cane quality for any of the fertilizer treatments used. 
57.

\section{9 - LITERATURA CITADA}

ALI, M. Y., 1966. Effect of phosphorus, silicon and zinc ap plications on the yield and mineral composition of sugarcane. M.S. Thesis, Univ. of Hawaii, $133 \mathrm{p}$.

AYRES, A., 1966. Calcium silicate slag as a growth stimulant for sugarcane on low-silicon soils. Soil Sci, 101: 216217 .

BAIR, R. A., 1966. Leaf silicon in sugarcane, field cornand St. Augustine grass grown on some florida soils. Proc. Soil Crop. Sci. Soc. Fla., 26: 64-70.

BARNETTE, M. R., 1924. Synthetic calcium silicate as a sour ce of agricultural lime: A comparasion of the influence of synthetic calcium silicate with other forms of lime as affecting plant growth. Soil Sci., 18: 479-491. 
BASSINELLO, A. I. ; S. MATSUOKA e A. C. MENDES, 1976. Varie dades de Cana-de-Açūcar para o Estado de São Paulo. Bol. Tec. no 3, Planalsucar, Araras (SP), 19 p.

CATANI, R. A. ; J.R. GALLO e H. GARGANTINI, 1955. Amostragem do solo, métodos de anālises, interpretação e indicações para fins de fertilidade. Bol. nọ 69. Inst. Agron. Campinas.

CHEONG, Y. W. Y., 1970. The residual effect of calcium sili cate applications on sugar cane growth. Ann. Rep. Mauri tius Sugar Industry Res. Inst., 23: 63-68.

CLEMENTS, H.F., 1965. The roles of calcium silicate slag in sugarcane growth. 1665. Reports, Hawaiian Sugar. Tech. p. 103-126.

CLEMENTS, H. F., 1967. Effects of silicate on the growth and leaf freckle of sugarcane in Hawail. Proc. Int. Sugar Cane Technol., Puerto Rico, 12: 197-215.

DEWAN, M. e A. S. HUNTER, 1949. Absorption of phosphorus by soybean and sudan grass. II. Effect of silicates. Soil Sci., 68: 479-482.

D'HOTMAN DE VILLIERS, 0., 1961. Soil rejuvenation whith crushed basalt in Mauritius I. Consistent results of world-wide inerest. Int. Sugar J., 63: 363-364.

ENGEL, W., 1958. Contribution to the function of silica in plant Tissues. Natur wi Scenceschaften, 45: 316-317. 
FISHER, R. A., 1929. A preliminary note on the effect of sodium silicate in increasing the yield of barley. J. Agric., 19: 132-139.

FOX, R. L. ; D. L. PLUCKNETT e A. S. WHITNEY, 1968. Phospha te requiriments of Hawaiian Latosols and residual effects of fertilizer requiriments. 9 th. Int. Congr. Soil Sci., Adelaide, Australia, 2: $301-310$.

FOX, R. L. ; J. A. SILVA ; O. R. YOUNG ; D. L. PLUCKNETT E G. D. SHERMAN, 1967. Soil and plant silicon and silicate response by sugarcane. Soil Sci. Soc. Amer. Proc., 31: $775-779$.

GALLO, J.R. ; P. R. FURLANI ; 0. C. BATAGLIA e R. HIROCE, 1974. Teores de Silicio em gramineas cultivadas e forrageiras. Ciência e Cultura, 26(3): 286-292.

GASHO, G. J. E H. J. ANDREIS, 1974. Sugar cane response to calcium silicate slag applied to organic and sand soils. Proc. 15 th. Congr., ISSCT, Durban, South Africa, 15 (2): $543-551$.

GLORIA, N. A. ; R. A. CATANI e T. MATUO, 1965. O método do EDTA na determinação do cálcio e magnésio trocável do solo. Rev. Agric., Piracicaba, 40: 67-74.

Guimaräes, E., 1974. Adubação da Cana-de-Açūcar. IV Semana Agronómica de Pinhal, $23 \mathrm{p}$.

GOMES, F.P., 1970. Curso de Estatística Experimental. Piracicaba, ESALQ/USP. $430 \mathrm{p}$. 
HALAIS, P. E D. H. PARISH, 1963. Silica and manganese content of cane sheats in relation to soil and nutrition. Mauritius Sugar. Ind. Res. Int. Annu. Rept. (1963): $74-76$.

HALL, A. D. E C. G. T. MORRISON, 1906. On the function of silica in the nutrition of cereals. Int. Proc. Roy Bot. Soc., 77: $455-477$.

HURNEY, A. P., 1974. Effect of silicates on cane growth. Cane Growers Quartely Bulletin, 373: 78-80.

HUSZ, G. S., 1972. Sugar Cane, Cultivation and Fertilization. University in Hobenbein, West Germany, Ruhr Stickstoff, $116 \mathrm{p}$.

JACKSON, M.L., 1958. Soil Chemical Analysis. Englewood Cliffs, N. J. Prentice Hall Inc. $498 \mathrm{p}$.

JONES, L. H.P. E K. A. HANDRECK, 1967. Silica in soils, plants and animals. Advances in Agronomy, 19: 107-149.

KHAN, D. H. A A. C. ROY, 1964. Growth, P uptake and fibre cell dimensions of jute plant as affected by silicate treatment. Plant and Soil, 20: $331-336$.

LEWIN, J. e E. F. REIMANN, 1969. Silicon and plant growth. Ann. Rev. Plant Physiol., 20: 289-304.

MENGEL, K. e E. A. KIRKBY, 1978. Principles of Plant Nutri cion. Switzerland. Int. Potash Institute. Berne, 20: $593 \mathrm{p}$. 
OKUDA, A. e E: TAKAHASHI, 1964. The role of silicon. In: The Mineral Nutrition of the Rice Plant. John Hopkins, Baltimore, Maryland, p. 123-146.

ORLANDO, F.J., 1976. Influência varietal e do solo no Esta do Nutricional da Cana-de-Açūcar (Saccharum sp) pela anālise foliar. Piracicaba, ESALQ/USP. 69 p. (Disserta ção de Mestrado).

PLUCKNETT, D. L., 1972. The use soluble silicate in Hawaian agriculture. Univ. of Queensland Papers, 1(6): 203-223.

RALEIGH, G. J., 1953. Some effects of various silicates, lime and gypsom on growth of tomato plants in Western and Eastern soils of low levels of phosphorus nutrition. Cornell Agric. Exp. Sta. Memo., 326: p. 78.

RAUPACK, M. e C.S. PIPER, 1959. Interactions of silicate and phosphate in a lateritic soil. Austr. J. Agric. Res., 10(6): $818-831$.

ROSS, K. ; P. NABASBSING e Y. WONG YOU CHEONG, 1974. Residual effect of calcium silicate applied to sugar cane soils. Proc. 15 th. Congr. ISSCT, Durban, South Africa, 15: $539-542$.

ROTHBUHR, L. e F. SCOTT, 1957. A study of the uptake of si1 icon and phosphorus by wheat plants with radio chemical methods. Biochem. J., 65: 241-245.

ROY, A. C., 1969. Phosphorus - silicon interactions in soils and plants. Dr. Thesis, Univ. of Hawai, $190 \mathrm{p}$. 
ROY, A. C. ; M. Y. ALI ; R. L. FOX e J.A. SILVA, 1971. Influence of calcium silicate on phosphate solubility and availability in Hawaiian Latosols. Int. Symposium on Soil. Fertility Evaluation. Proc. New Delhi India, 757-765.

SAMUELS, G., 1969. Foliar Diagnosis for Sugar Cane. Rio Piedras, Puerto Rico, $362 \mathrm{p}$.

SARRUGE, R. E H. P. HAAG, 1974. Anālises Químicas em Plantas. ESALQ/USP. Piracicaba, $55 \mathrm{p}$.

SHERMAN, G. D., 1969. Crop growth response to applications of calcium silicate to tropical soils in Hawaian Islands. Agricult. Digest., 18: 11-19.

SHIUE, J. J., 1964. A study on the silicon content in the soils of Tawaian Sugar Cane fields. Taiwan Sugar. Expt. Sta. Rep., 36: $109-116$.

TANIMOTO, T., 1964. The press method of cane analys is. Hawaii Plrs. Rec., 57(2): $133-50$.

VAN DELLEWIJN,C., 1952. Botanique de la Canne a Sucre, Wageninglen, Veennan \& Zonen, $391 \mathrm{p}$.

VETTORI, L., 1969. Metodos de anālise de solo. Minist. da Agric. Bol. Téc. nọ 7. $24 \mathrm{p}$. 